\title{
Two FE models to analyse the dynamic response of short span simply-supported oblique High-Speed railway bridges: comparison and experimental validation
}

\author{
P. Galvín ${ }^{* a}$, A. Romero ${ }^{a}$, E. Moliner ${ }^{\text {b }}$, M.D. Martínez-Rodrigo ${ }^{b}$ \\ ${ }^{a}$ Escuela Técnica Superior de Ingeniería, Universidad de Sevilla, Camino de los Descubrimientos s/n, \\ 41092 Sevilla, Spain \\ ${ }^{b}$ Universitat Jaume I, Department of Mechanical Engineering and Construction, Avda. Sos Baynat \\ s/n, 12071 Castellón, Spain
}

\begin{abstract}
In this paper the dynamic response of a particular type of High-Speed railway bridge common in the Spanish railway system is analysed with the aim of evaluating the levels of vertical vibrations experienced at the platform. To this end, Bracea I bridge which belongs to the Madrid-Sevilla High Speed railway line is selected. The bridge is composed by two identical short simply supported spans. The pre-stressed concrete girders deck dimensions and level of obliquity make this structure prone to (i) experience important vertical accelerations under railway traffic and (ii) present a dynamic response with a high participation of modes different from the longitudinal bending one. Therefore the structure is not expected to behave as a beam-type structure. The results of an experimental campaign recently performed at the site are presented with the objective of characterising the soil dynamic properties and the structure response under ambient vibration conditions and under railway traffic. The experimental response of the bridge is then compared in the time and frequency domains to numerical predictions given by two Finite Element models which adopt common assumptions in engineering practice. The study provides interesting conclusions regarding the structure experimental response under resonant and not resonant conditions. Additionally, conclusions regarding the adequacy of the numerical models for predicting the bridge response and assessing the Serviceability Limit State of vertical acceleration in ballasted railways are presented.
\end{abstract}

Key words: Railway bridges, experimental measurements, resonance, traffic induced vibrations, bridge dynamics, soil properties

\section{Introduction}

The evaluation of the dynamic effects caused by modern railway transportation systems on railway infrastructures is a key factor to guarantee structural integrity and travelling

\footnotetext{
${ }^{*}$ Corresponding author. Tel.: +34954487293

Email address: pedrogalvin@us.es (P. Galvín)

Preprint submitted to Engineering Structures
}

June 7, 2018 
comfort. At circulating speeds above $200 \mathrm{~km} / \mathrm{h}$, resonance effects caused by the regular nature of the train axle loads may entail harmful consequences on railway bridges, such as ballast destabilization, passenger discomfort or a raise in the maintenance costs of the line. Especially critical in this regard are short-to-medium span simply-supported (S-S) bridges with usually low associated structural damping and mass, which may experience considerably high vertical accelerations at the deck level $[1,2]$. In these structures the Serviceability Limit State of vertical acceleration is one of the most demanding specifications for their design or upgrading. These facts point out the importance of developing accurate numerical models, able to realistically predict the vibration levels on the bridge with reasonable computational costs.

Several research works on this topic have been presented in recent years. Liu et al. [3] and Doménech et al. [4] investigated the conditions under which train-bridge interaction should be considered for the dynamic analysis of a bridge under railway traffic. The authors identified key ratios between structural and vehicle properties that maximized the influence of the vehicle suspension systems on the bridge response. Ülker-Kaustell and Karoumi [5] studied the influence of variations in the bridge natural frequency and modal damping with the vibration amplitudes under resonance. The results indicated that these variations may considerably reduce the resonant amplitudes and the critical train speeds. Lu et al. [6] investigated the frequency contents in the bridge response as well as in the train excitation. They concluded that for short bridges, well-distributed frequency peaks occur at a number of dominant frequencies, whereas for longer bridges the main frequency peak tends to concentrate towards the lowest dominant frequency. Rocha et al. [7] used a probabilistic approach to analyse the sensitivity of the dynamic response of a short span bridge due to the variability of the main structural parameters. The Canelas Railway Bridge was used as case study. The procedure showed that the bridge deck sectional and mechanical properties, the mass of the ballast layer and the vertical stiffness of the supporting bearings were the parameters that most affected the bridge response. Ülker-Kaustell et al. [8] analysed the influence of soil-structure interaction (SSI) on the dynamic properties of a portal frame railway bridge by means of dynamic stiffness functions describing the stiffness and damping of the foundation-soil interface. Romero et al. [9] also studied the dynamic soil-bridge interaction in HighSpeed (HS) railway lines. The authors concluded that SSI affects the structure dynamic behaviour, and showed how the fundamental period and damping ratio of the structure substantially increased when SSI was considered. Gu [10] presented a vehicle-bridge numerical model including the coaches suspension systems for traffic analysis under realistic conditions. This model revealed that TGV trains operating in France, Korea and in the UK on long-span bridges were highly vulnerable to resonance. Moreover, the author mentioned that the design codes are not yet available for designing long-span railway bridges with low natural frequencies. Cantero and Karoumi [11] numerically investigated the consequences of assuming that the maximum load effect in S-S railway bridges happens at mid-span, with particular attention to resonant situations. The authors found that significant errors appear when the relative energy content of the higher modes of vibration is high, for example, when one of the bridge higher natural frequencies matches a loading frequency. Doménech et al. [12] developed a numerical investigation analysing the effects of SSI on the free vibration response of simply-supported beams in a wide range of travelling velocities. This study justified how resonant amplitudes of the bridge under the circulation of railway convoys may be affected by the soil properties, leading 
to substantially amplified responses or to almost imperceptible ones, from the conditions of maximum free vibration and cancellation of the deck response. Bebiano et al. [13] applied a semi-analytical formulation for the dynamic analysis of a real $46 \mathrm{~m}$ span thinwalled HS railway bridge. From this study the authors concluded that local deformation modes have influence on the dynamic response of thin-walled decks.

In order to realistically predict the response of a bridge under railway traffic the calibration of numerical models with in situ dynamic testing becomes crucial. With this purpose a number of researchers have performed experimental campaigns on railway bridges in the past. Xia et al. [14] presented the results of dynamic experiments on the Antoing Bridge located on the HS railway line between Paris and Brussels. Modal parameters, strains and vertical and lateral accelerations were identified from measurements. Marefat et al. [15] carried out dynamic and static load tests to evaluate the remaining strength of a plain concrete arch bridge. The bridge showed a relatively large energy absorption capacity and did not experience any resonance effects. Rebelo et al. [16] presented the results of experimental measurements on a number of existing small to medium length single span ballasted railway bridges in Austria. From the tests, the authors concluded that the damping due to friction between the ballast particles and at the supports considerably affects the maximum acceleration. Also, the fundamental frequencies of the bridges vary with the amplitude of the vibration, that is, increasing vibration amplitudes lead to a decrease in the first natural frequency in a consistent way for all investigated bridges. Flener and Karoumi [17] experimentally studied the dynamic response of an $11 \mathrm{~m}$ span corrugated steel culvert railway bridge. The tests showed that the train speed had an important influence on the bridge response. Dynamic amplifications higher than the values specified in bridge design codes were measured, even though this type of bridge structure seems less sensitive to resonance effects due to its inherent high damping. Liu et al. [18] presented in situ dynamic measurements and an experimental validation of the numerical model of the Sesia composite viaduct for the prediction of HS train-induced vibrations. This study provided a better understanding of the structural behaviour of composite railway bridges under the excitation of High-Speed trains (HST). Kim et al. [19] proposed a methodology for estimating modal parameters from the free vibration response immediately after the train passage. The technique was successfully validated in a two-span steel composite girder bridge. Wallin et al. [20] studied the Söderström steel Bridge, located in the city of Stockholm. A 3D finite element (FE) model was implemented and verified with measurements. The strengthening methods considerably improved the fatigue life of the bridge. A change in the structural system drastically modified the dynamic behaviour of the bridge and the deck acceleration levels. Vega et al. [21] presented a complete study of a culvert from the HS line between Segovia and Valladolid, in Spain, including on-site measurements and numerical modelling. Ribeiro et al. [22] presented the calibration of the numerical model of a bowstring-arch railway bridge based on modal parameters. Johansson et al. [23] examined three railway lines in the southern part of Sweden since the government was considering increasing the design speed from $200 \mathrm{~km} / \mathrm{h}$ to $250 \mathrm{~km} / \mathrm{h}$. The simplified numerical study covered 1000 bridges. A high number of these bridges, mainly with spans shorter than $12 \mathrm{~m}$, did not fulfill the code requirements. Malveiro et al. [24] carried out the calibration and experimental validation of the dynamic model of a railway viaduct with a precast deck. Costa et al. [25] calibrated a numerical model of a stone masonry arch railway bridge using dynamic modal parameters identified from ambient vibration tests. The authors used a genetic al- 
gorithm which allowed estimating the elastic properties of the materials. Park et al. [26] proposed an experimental method to measure the viscoelastic properties of the railway track under flexural vibrations using the wave propagation approach.

In the previous experimental studies the attention mainly focusses on the dynamic response of the bridge deck under ambient or train induced vibrations. However, as indicated in the cited literature, the dynamic response of short-to-medium span S-S railway bridges is difficult to predict during the design or upgrading stages, since the influence of environmental parameters and super-structure components (rails, ballast) can be significant and it is considerably uncertain. Additionally, in double track bridges, modes different from the longitudinal bending one (i.e. first torsion and transverse bending modes with close natural frequencies) may affect significantly the maximum response of the bridge. This is related to usual structural typologies in the range of lengths under consideration and to the ratio between the span length and the width of the deck. Despite the high vibration levels that such structures may experience, the number of reported experimental campaigns is scarce. Finally, even though some studies reveal that SSI may significantly affect the bridge dynamic response under certain conditions $[8,9,12]$, especially in the case of short S-S structures, the properties of the soil are seldom measured during the tests nor included in the numerical FE models. Only when the interaction between the super-structure and the soil is more evident due to the bridge typology, as it is the case of portal frames or soil-steel composite railway bridges [8, 27], SSI is taken into account.

In this work the results and conclusions from an experimental campaign performed on a short S-S bridge belonging to a HS railway line in Spain are included. This bridge is particularly interesting as (i) the structure presents a skew angle of $45^{\circ}$ and a span length similar to the deck width. For these reasons its dynamic response substantially differs from that of a beam-type structure; and (ii) in a preliminary numerical evaluation of the bridge [28], performed assuming the main simplifications adopted by practitioners in accordance with the European Standards [29, 30], an important transverse vibration response was predicted at the deck level. In the work presented herein, the tests performed aim to identify the soil properties at the site, the bridge modal parameters and the structural transverse response under different trains circulating at speeds comprised between 200 and $300 \mathrm{~km} / \mathrm{h}$, approximately. First, the effect of SSI is disregarded in a first approach based on the measurements. Then, two different FE numerical models, typical for this particular bridge typology, are implemented and calibrated from experimental results. Conclusions are finally extracted regarding: (i) the structure performance under resonant and not resonant conditions, and (ii) the adequacy of the numerical models implemented for the particular soil type at the site and the loading conditions.

\section{Bridge typologies}

In this section a general description of some of the concrete bridge decks that can be found in the Spanish High-Speed railway network is presented. Since short-to-medium span lengths simply-supported structures are particularly sensitive to railway induced vibrations, the usual typologies for these lengths are described in section 2.1. In section 2.2 , the main structural properties of Bracea I bridge, which is the object of analysis in this study, are included. 


\subsection{Short-to-medium span HST bridges}

Figure 1 shows some of the most usual concrete bridge decks traditionally found in railway bridges of short-to-medium spans. The simplest typology is the solid slab shown in Figure 1(a), common in urban surroundings for spans between $10 \mathrm{~m}$ and $15 \mathrm{~m}$ in Spain. It usually presents a slenderness ratio (depth/span) comprised between 1/12 and 1/14. These decks are usually built on site, although the use of prestressed decks is becoming more common. For longer spans, in order to reduce the dead weight, various forms of voided slabs (circular, rectangular, etc.) are also adopted. This solution is cost-effective for slab thicknesses higher than $120 \mathrm{~cm}$, and it has become frequent in the newest HS railway lines.

Figure 1(b) shows a pseudo-slab, composed by standard precast prestressed inverted $\mathrm{T}$ beams acting in conjunction with an in situ concrete slab. As for the solid slabs, this type of deck is not usually found for spans longer than $15 \mathrm{~m}$. At present, solutions based on precast prestressed concrete girder bridges (Figure 1(c)) are less usual in HS lines, since they exhibit lower resistance to torsion when compared to other solutions. Despite this fact, a number of girder bridges were specifically built in the late 80's for the first HS railway line in Spain (Madrid-Sevilla), as it is the case of the bridge studied in this work, described in subsection 2.2. This type of deck is also common in conventional lines which, according to current trends, are often upgraded to higher design speeds. This typology, composed by several precast prestressed beams with a reinforced concrete, cast-in-place upper slab, usually covers span lengths between $10 \mathrm{~m}$ and $25 \mathrm{~m}$, with slenderness ratios lower than 1/13. Finally, the search for bridge structures with good torsional and flexural strengths has led to the adoption of box and twin-box girder bridges (Figure 1(d)), composed by one/two precast prestressed U-shaped girders and a reinforced concrete cast in place upper slab. This solution is very common in the latest High-Speed lines for spans higher than $20 \mathrm{~m}$ and slenderness ratios in the vicinity of $1 / 11$.

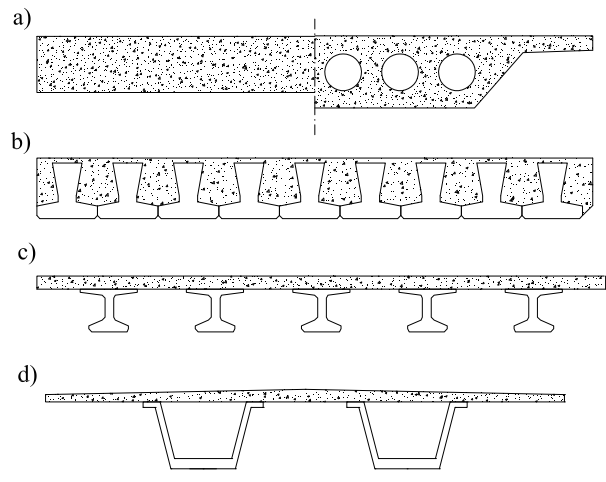

Figure 1: Types of concrete bridge decks.

In summary, bridge decks of types shown in Figure 1(a),(b) and (c) are rather common in conventional railway lines $(V \leq 200 \mathrm{~km} / \mathrm{h})$. However, with the increase of the operating train velocity, some of these structures have also been adapted to High-Speed train services. The presence of voids in (a) and an additional longitudinal stiffness due to the longitudinal girders in (b) and (c) led to the development of models for bridge analysis such as the so called orthotropic plate models or the grillage models [31, 32]. In 
the orthotropic plate analysis, the actual deck is replaced by an equivalent orthotropic plate with different elastic properties in two orthogonal directions. These properties are computed from the real bridge deck geometry and mechanical properties. The grillage method replaces the bridge deck by a planar assembly of rigidly connected beams, arranged in either an orthogonal or a skewed assembly. The optimum number of longitudinal and transverse beams required in the model along with the computation of their elastic properties is a key issue that is also discussed in the literature [33].

In the case of double track girder decks with span to width ratios close to unity, the contribution of several modes, different from the longitudinal bending one, should be expected, especially when resonance is not induced on the bridge deck. In these situations beam models, commonly used in dynamic analysis of S-S structures under moving loads, may be far from accurate when compared to experimental measurements. The bridge under study, Arroyo Bracea I bridge, has been modeled using an orthotropic plate model in the past [28], therefore admitting a uniform distribution of stiffness and vertical flexibility along the supports. In this study, the adequateness of the orthotropic model is compared to that of an isotropic plate connected to beam elements representing explicitly the actual girders of the deck, and concentrated elastic supports for the deck bearings. The results given by both models are compared to experimental measurements under different loading conditions and conclusions are extracted about their adequateness.

\subsection{Arroyo Bracea I bridge in Madrid-Sevilla HS line}

The structure under study, designated as Arroyo Bracea I bridge (Figure 2), is a railway bridge composed by two identical S-S bays of $15.25 \mathrm{~m}$ equal spans. The bridge belongs to the Madrid-Sevilla High-Speed railway line, which was the first HS line in Spain opened in 1992. The structure crosses the Bracea stream with a $45^{\circ}$ skew angle. Each deck consists of a $25 \mathrm{~cm}$ thick, $11.6 \mathrm{~m}$ width concrete slab resting over five $1.05 \mathrm{~m}$ high prestressed concrete I girders. The girders lean on the supports through laminated rubber bearings. The slab carries two ballasted tracks with an equal eccentricity of $2.15 \mathrm{~m}$ from its longitudinal axis, two sidewalks and handrails (Figure 3). As per the substructure, the bridge deck is supported on reinforced concrete abutments in its outermost sections and the inner sections of both bays lean on a pile foundation.

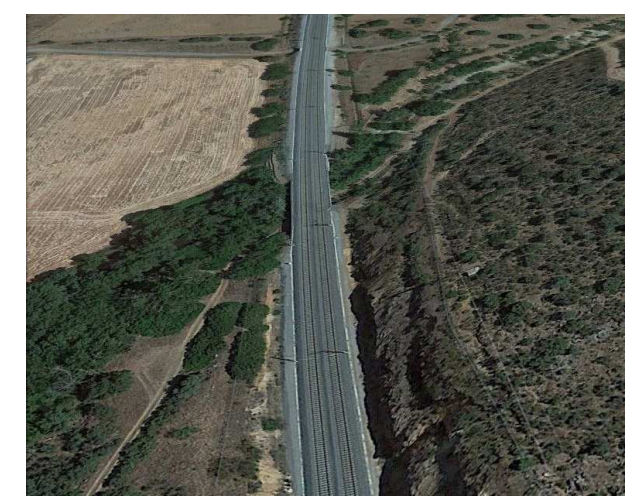

Figure 2: Arroyo Bracea I bridge (Image from Google Earth). 


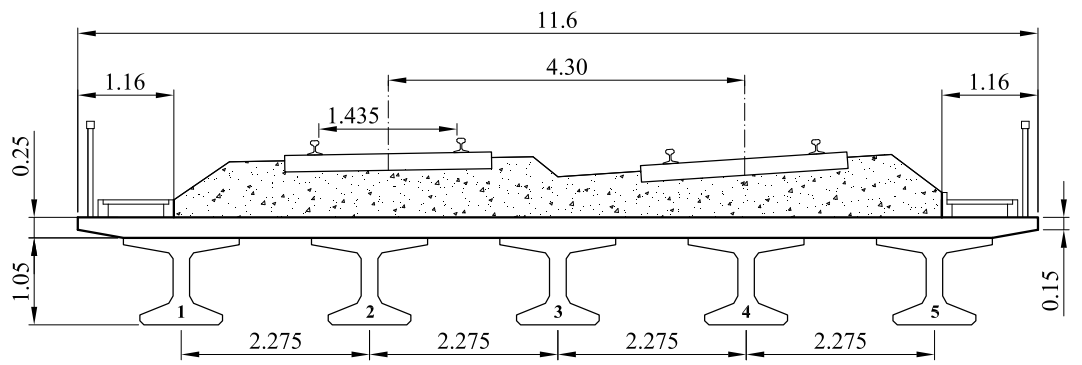

Figure 3: Arroyo Bracea I bridge deck cross section (Dimensions in $[\mathrm{m}]$ ).

The railway track is a classical ballasted track. The rails have a UIC60 cross section and are continuously welded. The rails are supported by rail pads and fixed with clips on monoblock concrete sleepers with a spacing of $d=0.60 \mathrm{~m}$. The concrete monoblock sleepers are $l_{s}=2.60 \mathrm{~m}$ long, $b_{s}=0.30 \mathrm{~m}$ wide at the base, and $h_{s}=0.24 \mathrm{~m}$ high. The total mass of the sleepers is $m_{s l}=533 \mathrm{~kg} / \mathrm{m}$ along each of the two tracks. The tracks are supported on a ballast layer with an approximate thickness $h_{b}$ of $0.30 \mathrm{~m}$. The density of the ballast layer has been considered $1800 \mathrm{~kg} / \mathrm{m}^{3}$.

\section{Numerical models}

\subsection{Orthotropic plate model}

In this section the main properties of an orthotropic plate FE model of the bridge implemented in ANSYS are presented. This model is used in the subsequent sections to reproduce the dynamic behaviour of the structure under railway traffic. The model main features are the following: (i) the deck behaviour is simulated by means of an orthotropic thin plate discretised in shell elements with 6 degrees of freedom (dof) per node; (ii) the laminated rubber bearings underneath the deck girders are introduced in the model as an equivalent vertical stiffness uniformly distributed along the abutments lines, through an elastic foundation stiffness using beam elements; (iii) different mass density elements are defined in order to concentrate the weight of the ballast, sleepers and rails over the central portion of the plate; (iv) a point load model is adopted for the railway excitation, therefore neglecting vehicle-structure interaction effects; (v) the dynamic equations of motion are transformed into modal space and numerically integrated by the NewmarkLinear Acceleration algorithm. The time-step is defined as 1/25 times the smallest period used in the analysis (mode contributions up to $30 \mathrm{~Hz}$ are required according to European Standards [30]). This small value avoids period elongation errors and guarantees (i) that the peak responses are accurately predicted and (ii) that the oscillations of the modal loading functions are properly captured for the circulating speeds considered and for the maximum number of modes included in the analysis.

As the track rigidity is not included in the numerical model, and in order to avoid unrealistic high-frequency modal contributions when a load enters or exits the bridge due to the presence of the elastic bearings, the gradual nature of the wheel loads application process close to the abutments due to the distributive effect of rails, sleepers and ballast, is simulated. For this purpose, the value of each axle load is modulated at the deck 
entrance and exit vicinity by applying a function based on the Zimmerman-Timoshenko solution for an infinite beam on Winkler foundation [28].

The computation of the orthotropic plate constants from the real bridge deck mechanical properties, is not included in this document for the sake of brevity, but it is explained with detail in literature (see $[31,32])$.

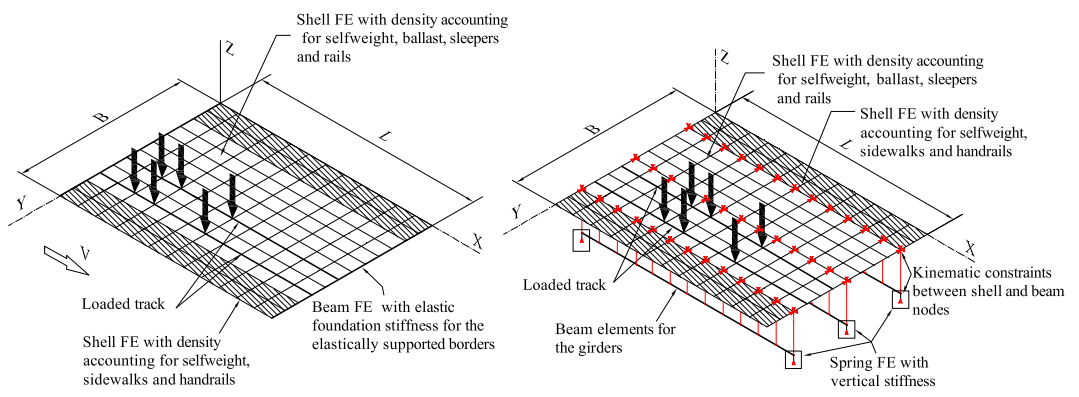

Figure 4: Orthotropic (left) and isotropic (right) plate + beams models.

In Table 1 the main properties of the orthotropic plate calibrated model previously described are summarized. $E_{x}, E_{y}, \mu_{x}, \mu_{y}$ and $G_{x y}$ stand for the Elastic Modulus and Poisson's ratio in the longitudinal and transverse directions, respectively, and for the Shear Modulus. On the right column of the table, $M_{\text {plate }}$ is the total mass per unit length of the plate, $\rho_{\text {plate }, 2}$ and $\rho_{\text {plate }, 1}$ are the mass densities assigned to the central portion of the plate, including the weight of the platform, and to the sides, respectively. Finally, $\bar{k}_{v, s t}$ and $\bar{k}_{v, d y n}$ are the values for the vertical elastic stiffness associated to the neoprene bearings distributed along the abutments, for static and dynamic loads, respectively.

\begin{tabular}{|l|l||l|l|}
\hline \multicolumn{2}{|l|}{ Orthotropic elastic constants } & \multicolumn{2}{|c|}{ Plate mass and elastic supports } \\
\cline { 4 - 4 }$E_{x}(\mathrm{~Pa})$ & $3.493 \mathrm{E} 12$ & $M_{\text {plate }}(\mathrm{kg} / \mathrm{m})$ & 26256 \\
\hline$E_{y}(\mathrm{~Pa})$ & $3.988 \mathrm{E} 10$ & $\rho_{\text {plate }, 1}\left(\mathrm{~kg} / \mathrm{m}^{3}\right)$ & 5735 \\
\hline$\mu_{x}$ & 0.2 & $\rho_{\text {plate }, 2}\left(\mathrm{~kg} / \mathrm{m}^{3}\right)$ & 9883 \\
\hline$\mu_{y}$ & $2.3 \mathrm{E}-3$ & $\left.\bar{k}_{v, s t} \mathrm{~N} / \mathrm{m}^{2}\right)$ & $2.1 \mathrm{E} 8$ \\
\hline$G_{x y}(\mathrm{~Pa})$ & $2.884 \mathrm{E} 10$ & $\bar{k}_{v, d y n}\left(\mathrm{~N} / \mathrm{m}^{2}\right)$ & $3.15 \mathrm{E} 8$ \\
\cline { 4 - 5 } & &
\end{tabular}

Table 1: Orthotropic plate model properties.

The properties of the previously described orthotropic plate model and those of the isotropic plate + beams FE model included in Section 3.2 were first obtained from the structure project. In 1991, right after the bridge construction, an experimental campaign was performed based on static, quasi-static and dynamic tests in order to verify the structure performance. The numerical models parameters are updated from these experimental results. Details of the calibration process may be consulted in [28].

\subsection{Isotropic plate + beams model}

An alternative FE model for the bridge has also been implemented. Two particular features of Bracea I deck could put into doubt the suitability of the orthotropic plate model: its marked obliquity ( $45^{\circ}$ skew angle) and the reduced number of longitudinal 
girders. Also, as it will be shown in what follows, five modes are experimentally identified with natural frequencies below $30 \mathrm{~Hz}$. This is related to the deck geometry (especially to the skew angle) and to the length to width ratio of the bridge deck in plan. Consequently, as it will be seen in Section 5, the dynamic behaviour of Bracea I bridge under the passage of HST exhibits a clear contribution of three-dimensional vibration modes (different to longitudinal bending ones), such as the first torsion or first transverse bending modes.

Under these circumstances, the boundary conditions adopted in the orthotropic plate model, in which two opposite borders of the deck are elastically supported, could lead to a poor prediction of the real dynamic behaviour of the structure.

An isotropic plate model with explicitly simulated longitudinal girders is implemented with the aim to analyse the adequacy of both models. As can be seen in Figure 4, the bridge girders are included in the model as beam elements with 6 dof per node. The girder nodes are connected to the upper plate by means of rigid kinematic constraints that couple the dofs of the beam nodes to those of the plate nodes right above them. The distance between the plate and the beams nodes equals the real separation between the slab neutral plane and the center of mass of the girders. In this model the laminated rubber bearings of the bridge are introduced in discrete positions by means of longitudinal springs with elastic vertical stiffness; these connect the $Z$ displacement of the end nodes of the bridge girders to the abutments, which are considered as fixed reference in the model.

As regards the upper plate, the only difference with respect to the orthotropic plate model is that the shell elements have isotropic mechanical properties in this case, representing those of the concrete slab. Finally, the railway excitation and the integration scheme to solve the dynamic equations of motion are the same in both models. In Table 2 the main properties of the isotropic plate + beams model previously described are summarized. $E_{\text {plate }}$ and $\mu_{\text {plate }}$ are the isotropic plate Elastic Modulus and Poisson's ratio, respectively, representing the slab, $\rho_{p l a t e}, m_{a d 1}$ and $m_{a d 2}$ are the plate mass density and the added masses accounting for the platform and sidewalks extra weight uniformly distributed over the central portion and the sides of the plate, respectively. Also, $k_{v, s t}$ and $k_{v, d y n}$ stand for the elastic vertical stiffness of the concentrated supports considered for static and dynamic loads. On the right hand side of Table 2, the girders properties are included (from top to bottom: moment of inertia with respect to the horizontal/vertical axes of the cross-section, torsion modulus, area, Elastic Modulus and mass density).

\begin{tabular}{|l|l||l|l|}
\hline \multicolumn{2}{|c|}{ Isotropic plate properties } & \multicolumn{2}{|c|}{ Longitudinal beams properties } \\
\hline$E_{\text {plate }}(\mathrm{Pa})$ & $3.99 \mathrm{E} 10$ & $I_{x, h}\left(\mathrm{~m}^{4}\right)$ & 0.0880 \\
\hline$\mu_{\text {plate }}$ & 0.2 & $I_{x, v}\left(\mathrm{~m}^{4}\right)$ & 0.0428 \\
\hline$\rho_{\text {plate }}\left(\mathrm{kg} / \mathrm{m}^{3}\right)$ & 2500 & $J_{x}\left(\mathrm{~m}^{4}\right)$ & $8.467 \mathrm{E}-3$ \\
\hline$m_{\text {adl }} m_{\text {ad } 2}\left(\mathrm{~kg} / \mathrm{m}^{2}\right)$ & 232,1015 & $A_{x}\left(\mathrm{~m}^{2}\right)$ & 0.5355 \\
\hline$k_{v, s t}(\mathrm{~N} / \mathrm{m})$ & $7.0 \mathrm{E} 8$ & $E_{x}(\mathrm{~Pa})$ & $4.6 \mathrm{E} 10$ \\
\hline$k_{v, d y n}(\mathrm{~N} / \mathrm{m})$ & $1.4 \mathrm{E} 9$ & $\rho_{x}\left(\mathrm{~kg} / \mathrm{m}^{3}\right)$ & 2500 \\
\hline
\end{tabular}

Table 2: Isotropic plate + beams model properties.

Regarding the computational cost, since the number of dof in the isotropic plate + beams model is greater than in the orthotropic plate model, the extraction of natural frequencies and mode shapes is, as expected, more time consuming in the former case, though not significant enough to be considered as an issue. Additionally, the modal 
analysis is followed by the numerical integration of the equations of motion under the passage of the train in modal space. The computational cost of this second step is equal in both models, as it does not depend on the number of nodes of the model but on (i) the number of modal contributions included in the analysis (which are practically the same in both models) and on (ii) the highest frequency considered (30 Hz in both models). Therefore, concerning computational costs, the differences between the two models are not significant.

\section{Experimental campaign}

On the $22^{\text {nd }}$ and the $23^{\text {rd }}$ of July 2016 the authors carried out an experimental campaign with the purpose of characterising the structure and soil dynamic properties along with the bridge dynamic response under railway traffic. In this section the campaign and the main results derived from it are described.

As per the acquisition equipment, a portable acquisition system LAN-XI of Brüel \& Kjaer was used. The acquisition system fed the sensors (accelerometers) and an instrumented impact hammer in the case of the soil tests. It also performed the Analog/Digital conversion (A/D). The A/D was carried out at a high sampling frequency that avoided aliasing effects using a low-pass filter with a constant cut-off frequency. The sampling frequency was $f_{s}=4096 \mathrm{~Hz}$. The acquisition equipment was connected to a laptop for data storage. Endevco model 86 piezoelectric accelerometers were used with a nominal sensitivity of $1000 \mathrm{mV} / \mathrm{g}$ and a lower frequency limit of approximately $0.1 \mathrm{~Hz}$. The same accelerometers were used for measuring the bridge response due to train passages and ambient loads. The acquisition system was configured to avoid sensor overload.

\subsection{Soil properties characterisation}

The dynamic characterisation of the soil was carried out by the seismic refraction and the Spectral Analysis of Surface Waves (SASW) tests. The seismic refraction test allowed the identification of the P-wave velocity $\left(C_{p}\right)$ of the soil layers. The SASW test was used to determine the $\mathrm{S}$-wave velocity $\left(C_{s}\right)$ and the material damping ratio of the soil layers ( $\beta$ ) $[34]$.

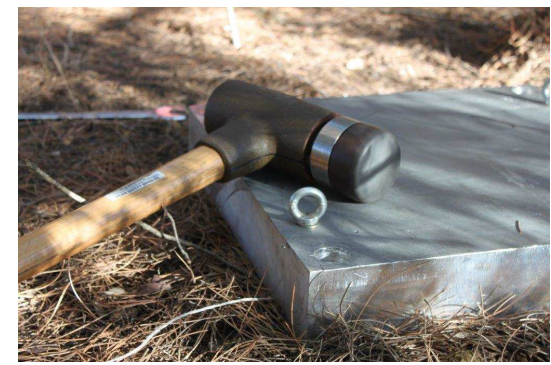

(a)

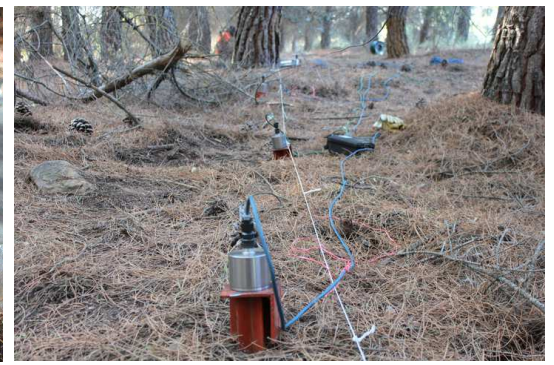

(b)

Figure 5: SASW test: (a) impact hammer and aluminium foundation; (b) accelerometers setup.

The measurements were performed in 2 complementary setups. In each set-up, 100 hammer impacts were applied to a $50 \mathrm{~cm} \times 50 \mathrm{~cm} \times 8 \mathrm{~cm}$ aluminium foundation anchored 
to the soil surface (Figure 5). The instrumented hammer included a PCB 086D50 force sensor. The vertical free field response was recorded by means of accelerometers anchored to the soil surface every $2 \mathrm{~m}(2 \mathrm{~m}$ to $68 \mathrm{~m}$ distant from the foundation limited by the bridge surrounding). Steel stakes of cruciform section and $30 \mathrm{~cm}$ of length were driven into the ground surface and each of the accelerometers was screwed to a stake. After each impact, a time signal of 16348 samples $(4 \mathrm{~s})$ was stored. The force channel was used as a trigger, with a trigger level of $10 \mathrm{~N}$, a pre-trigger of 4096 samples (or $1 \mathrm{~s}$ ), and a post-trigger of 12288 samples (or $3 \mathrm{~s}$ ). The signals were finally decimated (order 4), filtered with a third-order Chebyshev filter with a high-pass frequency of $1 \mathrm{~Hz}$ and a low-pass frequency of $100 \mathrm{~Hz}$.

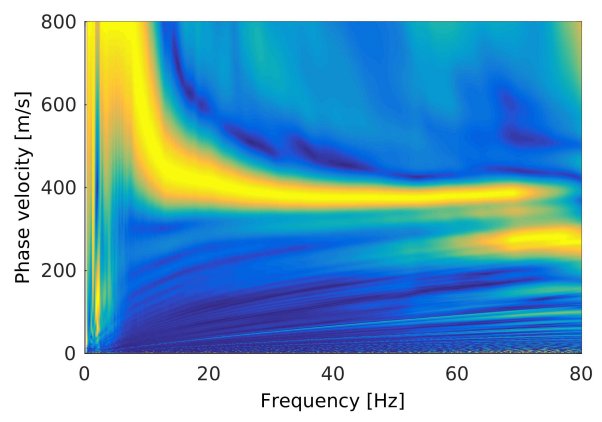

Figure 6: Dispersion curve.

Figure 6 shows the resulting dispersion curve. The maxima in the spectrum are due to the Rayleigh waves. Table 3 shows the soil properties obtained from the resolution of the inverse problem using the elastodynamics toolbox (EDT) from Schevenels et al. [35]. The soil in the surroundings of Arroyo Bracea I bridge is composed of an upper layer of quartz gravel of approximately $2 \mathrm{~m}$ on a compacted sandy gravel halfspace. The high value of the $\mathrm{P}$-wave velocity indicates that the soil is saturated. The profile is consistent with that provided by a geotechnical analysis performed at the site prior to the bridge construction [36].

\begin{tabular}{|c|c|c|c|c|c|}
\hline Layer & $\mathrm{h}[\mathrm{m}]$ & $C_{p}[\mathrm{~m} / \mathrm{s}]$ & $C_{s}[\mathrm{~m} / \mathrm{s}]$ & $\rho\left[\mathrm{kg} / \mathrm{m}^{3}\right]$ & $\beta[-]$ \\
\hline 1 & 2 & 900 & 250 & 1900 & 0.03 \\
2 & $\infty$ & 1750 & 430 & 1900 & 0.05 \\
\hline
\end{tabular}

Table 3: Identified soil properties.

From the previous results, due to the high stiffness of the soil, soil-structure interaction is not expected to affect the dynamic response of the bridge

First, the modal parameters of the bridge were identified from ambient vibration data by state-space models using MACEC software [37]. The ambient vibration response was 

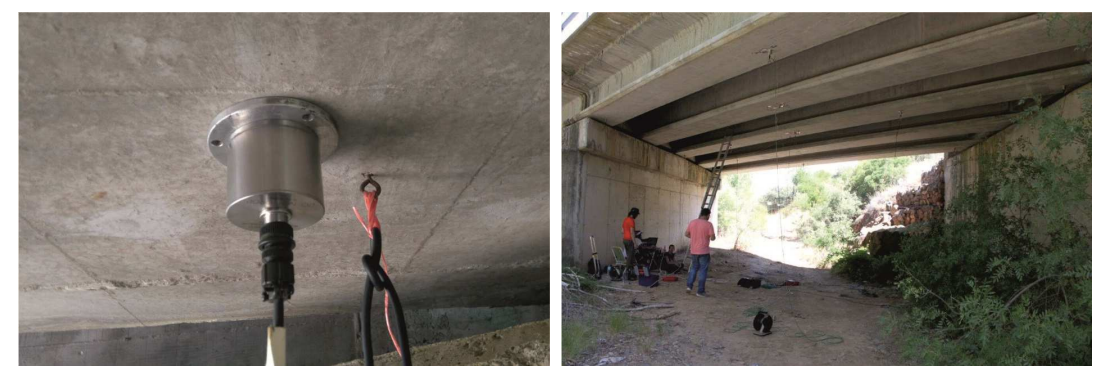

Figure 7: Accelerometers setup.

acquired in 4184 seconds per channel. Data were decimated (order 16) to carry out data analysis in the frequency range of interest $(0$ to $30 \mathrm{~Hz})$. The signals were filtered applying two third-order Chebyshev filters with high-pass and low-pass frequencies of $1 \mathrm{~Hz}$ and $30 \mathrm{~Hz}$, respectively. Figure 9 shows the stabilization diagram obtained from MACEC, where stable natural frequencies of the structure may be identified.

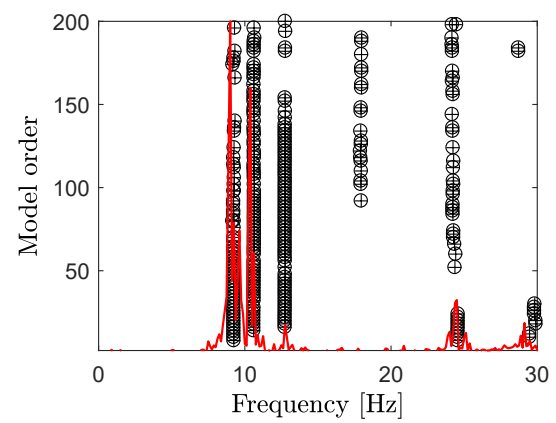

Figure 8: Stabilization diagram. Markers mean stable frequency.

The deck presents five modes in the previously mentioned frequency range, where the lowest ones in frequency order correspond to the first longitudinal bending, first torsion and first transverse bending mode shapes. In Table 4 the identified natural frequencies and the damping ratios are included for the first five modes. The identified damping for the fundamental mode reaches $2.0 \%$, higher value than that prescribed by standards for design purposes for this length and bridge typology [30].

The numerical natural frequencies provided by the FE models are included as well. The correlation between numerical and experimental mode shapes according to Modal Assurance Criterion (MAC) values [38] is also indicated. MAC values vary from 0 to 1 ; $\mathrm{MAC}=1$ implies perfect correlation between the two mode vectors (one vector is proportional to the other), while a close to zero MAC value indicates that the modes are not correlated (orthogonal modes). The Modal Phase Collinearity (MPC) [39] values higher than 0.95 show the consistency of structural modal parameters identified from the ambient vibration response. The numerical models predict the deck natural frequencies with errors lower than $5 \%$ in the orthotropic model case and lower than $8 \%$ in the case of the isotropic plate + beams model. The experimental and numerical mode shapes are 
represented in Figure 10 for the first five natural frequencies. AutoMAC values for these mode shapes show a very good correspondence with the real mode shapes. Both models provide values higher than 0.95 for the 1 st, 3 rd and 5 th modes. The isotropic plate + beams model shows a slightly worse correspondence for the torsion mode and so does the orthotropic plate model with de 4th modal shape. Nevertheless, it can be concluded that the correspondence between numerical and experimental results is reasonably accurate for both numerical models.
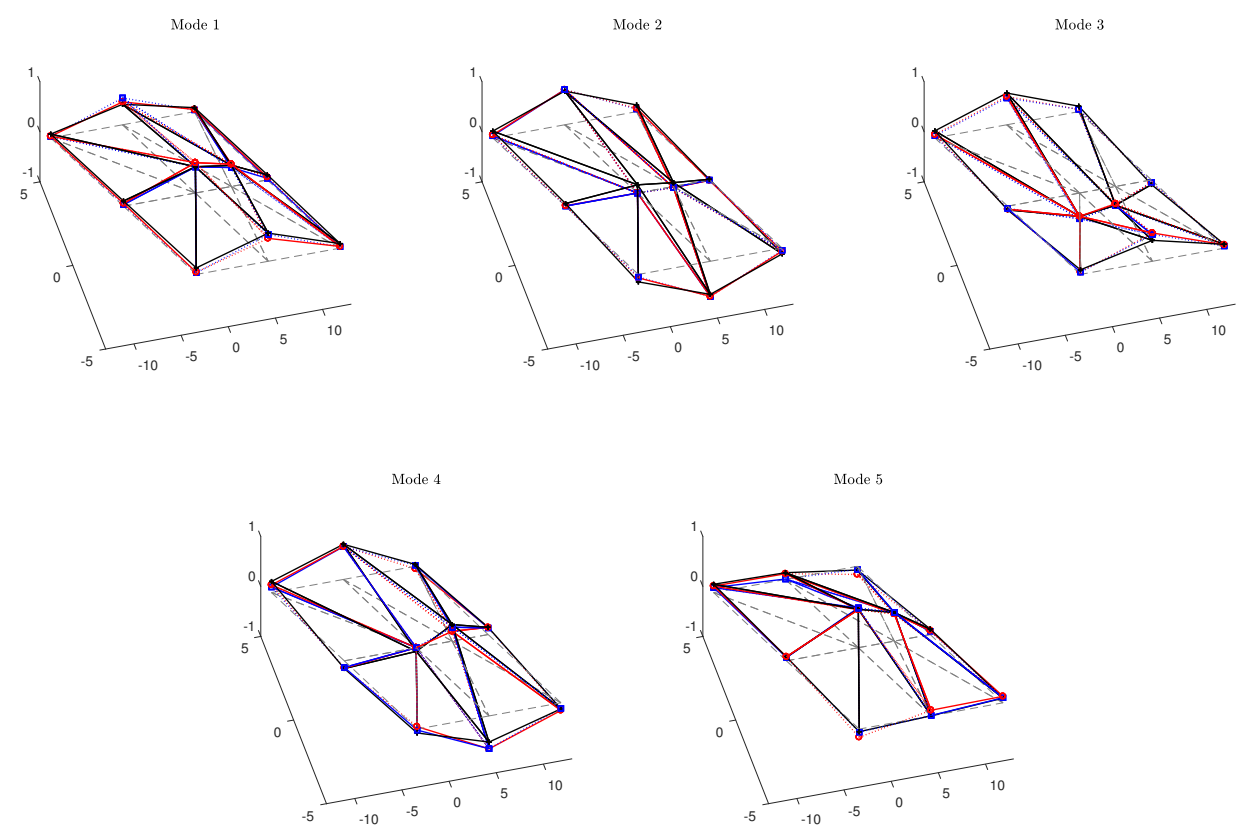

Figure 9: Experimental (black solid line) vs. orthotropic (red dotted line) and isotropic plate + beams (blue dotted line) numerical models first five identified mode shapes. Undeformed shape (dashed grey line).

\begin{tabular}{|c|c|c|c|c|c|c|c|}
\hline & $f_{\exp }[\mathrm{Hz}]$ & MPC [-] & $f_{\text {orto, num }}[\mathrm{Hz}]$ & $f_{\text {iso }, \text { num }}[\mathrm{Hz}]$ & $\xi_{\exp }[\%]$ & AutoMAC $\mathrm{Mxp}$, ort $[-]$ & AutoMAC $_{e x p, i s o}[-]$ \\
\hline 1 & 9.25 & 0.99 & 9.19 & 9.13 & 2.0 & 0.96 & 0.95 \\
\hline 2 & 10.63 & 0.97 & 10.34 & 9.86 & 1.61 & 0.94 & 0.93 \\
\hline 3 & 12.75 & 0.99 & 12.65 & 11.83 & 1.30 & 0.96 & 0.95 \\
\hline 4 & 17.92 & 0.99 & 17.20 & 16.71 & 0.80 & 0.93 & 0.96 \\
\hline 5 & 24.57 & 0.99 & 24.81 & 24.62 & 0.95 & 0.96 & 0.98 \\
\hline
\end{tabular}

Table 4: Experimental and numerical natural frequencies, experimental modal damping ratios, AutoMAC and MPC values.

The most significant difference between the modal frequencies predicted by the models is the torsion mode natural frequency. The presence of transverse beams bracing the 
longitudinal girders along the deck edges at the supports, which is not included in the numerical models, may justify this difference. In the authors' opinion, this issue should be investigated in future works.

\subsection{Train configurations}

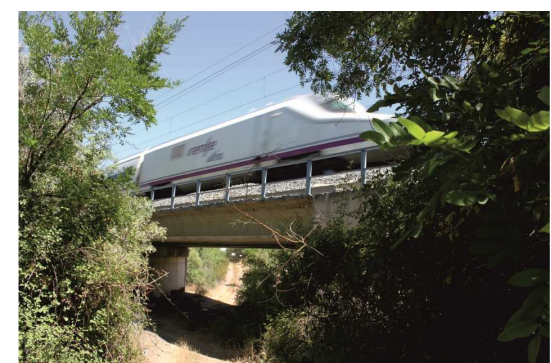

(a)

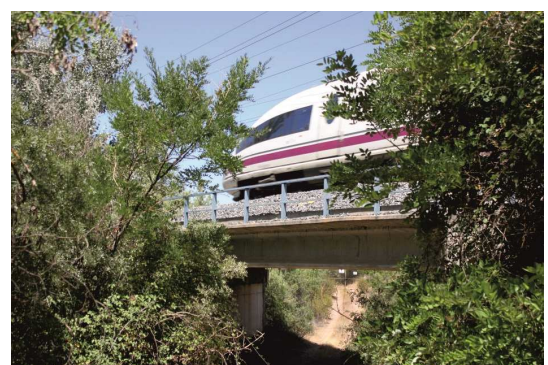

(b)

Figure 10: Arroyo Bracea I Bridge. Experimental campaign images: (a) RENFE Class 102 (Talgo 350) train passage at $v=263 \mathrm{~km} / \mathrm{h}$ and (b) RENFE Class 103 (ICE 3) train passage at $v=279 \mathrm{~km} / \mathrm{h}$.

During the recording time, several trains crossed the bridge with circulating velocities in the range $[100,280] \mathrm{km} / \mathrm{h}$ (Figure 11). In the next section the response of the bridge is presented for five of these trains: RENFE Class 100 (S100), 102 (Talgo 350 or S102), 103 (ICE 3 or S103), 104 (S104) and 130 (Talgo 250 or S130).

Figure 12 shows the axle schemes and coach distribution. Also the axle distances $d$ and axle loads $P$ are provided. RENFE Class 100 train is made up of two driving cars with two motorized bogies each and eight passenger cars with shared bogies, with a coach distribution type L-1-6x2-1-L. Class 102 and 130 have both two power cars, and are similar in what concerns coach distributions and axle schemes, yet with different type of locomotives and number of passenger cars. The coaches distributions are, respectively, L1-10x2-1-L and L-1-9x2-1-L. Finally, Class 103 (ICE 3) and 104 have distributed traction, with powered bogies located in alternate carriages, being the coach distributions 1-6x2-1 (eight cars: driver and passenger integrated cars at each end) and 1-2x2-1, respectively.

\subsection{Bridge response under HS traffic. Detection of resonances}

Figure 13 shows the vertical acceleration time history response and its frequency content recorded at sensor 5 (see Figure 7) for all the train passages: S100 at $v=262 \mathrm{~km} / \mathrm{h}$, $\mathrm{S} 102$ at $v=263 \mathrm{~km} / \mathrm{h}, \mathrm{S} 103$ at $v=279 \mathrm{~km} / \mathrm{h}, \mathrm{S} 104$ at $v=252 \mathrm{~km} / \mathrm{h}$ and $\mathrm{S} 130$ at $v=247 \mathrm{~km} / \mathrm{h}$. According to the measurements, the overall maximum acceleration occurs at this point, reaching $1.03 \mathrm{~m} / \mathrm{s}^{2}$ when the $\mathrm{S} 103$ train crosses the structure. Therefore, the Serviceability Limit State of maximum acceleration for ballasted tracks is accomplished $\left(a_{\max }<3.5 \mathrm{~m} / \mathrm{s}^{2}\right)$.

In the frequency domain peaks coinciding with the bogie passing frequency $f_{b}=v / L_{b}$ ( $L_{b}$ is the characteristic distance between two bogies) and with the natural frequencies of the structure may be detected. In order to interpret the results, the theoretical resonant velocities associated to the length of the passengers cars have been calculated for the first 


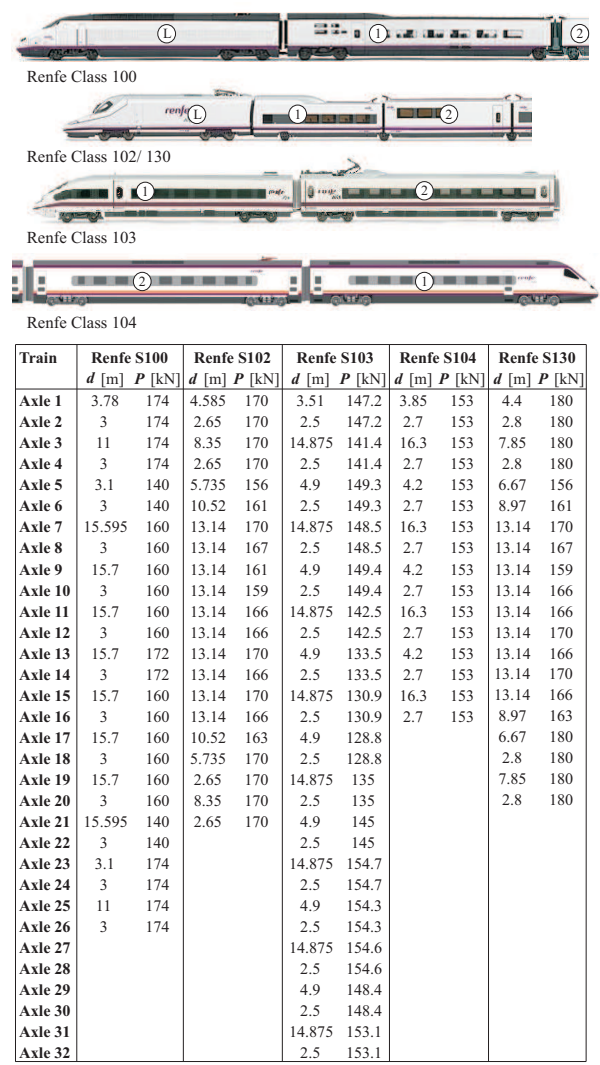

Figure 11: Trains coach distribution and axle distances.

and second modes in frequency order (first longitudinal bending and first torsion modes) as:

$$
v_{n, i}^{r e s}=\frac{d_{c a r} * f_{n}}{i} \quad n=1,2 \quad \text { and } \quad i=1,2,3
$$

In Equation $1 n$ stands for the mode number and $i$ for the resonance order. The resonance order should be understood as the number of cycles in a particular mode that the structure undergoes while repetitive groups of loads separated by the charateristic distance cross the bridge. In Table 5 the first, second and third resonant velocities for the fundamental longitudinal bending mode and for the first torsion mode of the bridge deck are included for the five trains. The characteristic distance and circulating velocity are included as well to facilitate the comparison. The characteristic distance could be any repetitive distance, but the length of the passengers coaches has been selected as it is the one usually associated with maximum acceleration values when resonance takes place [28]. Two resonant velocities in the vicinity of the circulating velocities are detected and shaded in Table 5: the third resonance of the fundamental mode associated to train S103 at $275 \mathrm{~km} / \mathrm{h}$ (very close to the real velocity of $279 \mathrm{~km} / \mathrm{h}$ ); and the second resonance of the second mode associated to the characteristic distance of train S130 at $251.4 \mathrm{~km} / \mathrm{h}$ (very close to the real velocity of $247 \mathrm{~km} / \mathrm{h}$ ). If these velocities do not coincide with 
cancellation conditions [40], the dynamic effects on the structure should be appreciable in the records. The $L / d_{\text {car }}$ ratio for the S103 train falls between the first and second cancellation of resonance conditions of a third resonance of the longitudinal bending mode of an elastically supported beam. Therefore this resonance will not be cancelled. On the other hand, the $L / d_{c a r}$ ratio for the S130 train does not coincide but it is proximate to the second cancellation condition of a second resonance of the fundamental mode of an elastically supported beam. Therefore this resonant peak should not be as evident as the one caused by the S103 train. Even though the real bridge deck behaves as a plate, as both the first bending and first torsion modes present a sinusoidal amplitude variation along the axle loads paths, these ratios may be used as approximations of the cancellation conditions and may justify the amplitudes of the predicted resonances.
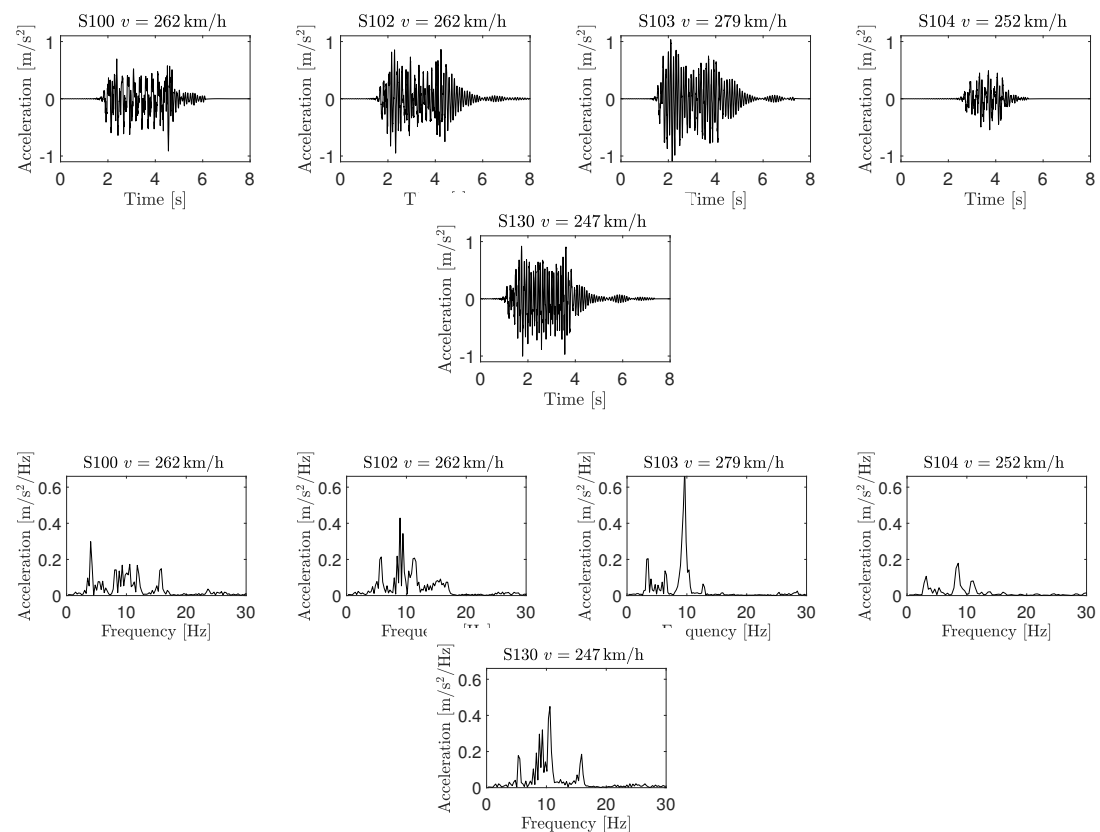

Figure 12: (Top) Time history and (bottom) frequency content of the acceleration at point 5 induced by S100, S102, S103, S104 and S130 Renfe class trains at different speeds.

From the analysis of Figure 13 it is noted that the circulation of S100, S102 and S104 trains does not induce resonance on the bridge deck. In these cases, the participation of several modal contributions can be detected in the deck response below $30 \mathrm{~Hz}$. On the other hand, S103 train travelling at $279 \mathrm{~km} / \mathrm{h}$ indeed induces a third resonance of the fundamental mode of the bridge associated to the length of the cars repetitive distance $\left(d_{c a r}=24.775 \mathrm{~m}\right)$. This peak is clearly perceptible in all the records. Although for this particular train this situation is not associated to inadmissible acceleration levels, a progressively increasing response of the structure with the axles passage is observed. Additionally, the peak associated to the resonant mode (fundamental) predominates in the frequency response and the contribution of other frequency contents is less relevant in comparison. As per the circulation of train S130, the comparison of the response measured at sensors 5 and 6 , which is presented in section 5 , shows a clear amplification 
of the deck torsional response. Also, in the frequency spectrum shown in Figure 13 it is noteworthy that the response at the second natural frequency exceeds the response associated to the fundamental one. This could be attributed to a second resonance of the torsion mode, although it is not so perceptible as that induced by train S103 associated to the fundamental mode of the bridge deck.

In the following section the response of the structure is presented in detail and compared to numerical predictions.

\begin{tabular}{r|r|r|r|r|}
\cline { 2 - 5 } \multicolumn{1}{c|}{$\operatorname{Train} \boldsymbol{v}(\mathbf{k m} / \mathbf{h})$} & $\boldsymbol{d}_{\text {car }}(\mathbf{m})$ & $\boldsymbol{v}_{1, \mathbf{1}}^{\text {res }}(\mathbf{k m} / \mathbf{h})$ & $\boldsymbol{v}_{1, \mathbf{2}}^{\text {res }}(\mathbf{k m} / \mathbf{h})$ & $\boldsymbol{v}_{1, \mathbf{3}}^{\text {res }}(\mathbf{k m} / \mathbf{h})$ \\
\hline $\mathbf{S 1 0 0} \mathbf{( 2 6 2 )}$ & 18.7 & 622.7 & 311.4 & 207.6 \\
\hline $\mathbf{S 1 0 2}(\mathbf{2 6 3})$ & 13.1 & 437.6 & 218.8 & 145.9 \\
\hline $\mathbf{S 1 0 3}(\mathbf{2 7 9})$ & 24.8 & 825.0 & 412.5 & $\mathbf{2 7 5 . 0}$ \\
\hline $\mathbf{S 1 0 4}(\mathbf{2 5 2})$ & 25.9 & 862.5 & 431.2 & 287.5 \\
\hline S130 (247) & 13.1 & 437.6 & 218.8 & 145.9 \\
\hline
\end{tabular}
Resonant speeds for mode 1 $\left(f_{1}=9.25 \mathrm{~Hz}\right)$

Resonant speeds for mode $1\left(f_{1}=9.25 \mathrm{~Hz}\right)$

\begin{tabular}{|c|r|r|r|r|}
\cline { 2 - 5 } \multicolumn{1}{c|}{ Train $\boldsymbol{v}(\mathbf{k m} / \mathbf{h})$} & $\boldsymbol{d}_{\text {car }}(\mathbf{m})$ & $\boldsymbol{v}_{2,1}^{\text {res }}(\mathbf{k m} / \mathbf{h})$ & $\boldsymbol{v}_{2,2}^{\text {res }}(\mathbf{k m} / \mathbf{h})$ & $\boldsymbol{v}_{2,3}^{\text {res }}(\mathbf{k m} / \mathbf{h})$ \\
\hline S100 (262) & 18.7 & 715.6 & 357.8 & 238.5 \\
\hline S102 (263) & 13.1 & 502.8 & 251.4 & 167.6 \\
\hline S103 (279) & 24.8 & 948.1 & 474.0 & 316.0 \\
\hline S104 (252) & 25.9 & 991.1 & 495.6 & 330.4 \\
\hline S130 (247) & 13.1 & 502.8 & $\mathbf{2 5 1 . 4}$ & 167.6 \\
\hline
\end{tabular}
Resonant speeds for mode $2\left(f_{2}=10.63 \mathrm{~Hz}\right)$

Table 5: First three resonant speeds for first and second modes associated to the length of the passengers cars.

\section{Comparison and experimental validation}

\subsection{Vertical response prediction in the time and frequency domains}

In Figures 14, 15 and 16 the vertical acceleration measured by sensors 5 (mid-span girder No.1), 6 (mid-span girder No.3) and 10 (second abutment girder No.3) are represented, respectively. Each row of plots in the figures corresponds to a particular train passage. The vertical acceleration at each point and for each train is plotted in the time domain (first column), frequency domain (second column) and in one-third octave frequency bands (third column). In all the plots, the experimental response is represented in black trace while the numerical predictions are plotted in blue and red traces for the isotropic plate + beams model and for the orthotropic plate model, respectively. The reader is advised to consult the electronic version of this document in order to fully distinguish the colour traces.

As it was expected, the vibrational response of the bridge is caused by several modal contributions apart from the longitudinal bending one. The deck length to width aspect ratio and its obliqueness cause the bridge behaviour to differ from that of a beam type structure. This may be apparent from the comparison of the responses at sensors 5 (Figure 14) and 6 (Figure 15), for the frequency contents between 10 and $15 \mathrm{~Hz}$ (frequency interval of the first torsion and first transverse bending modes).

As already introduced in the previous section, the bridge undergoes a clear resonance under the circulation of train S130-ICE3 at $279 \mathrm{~km} / \mathrm{h}$. This is apparent from the progressively increasing response perceptible in the acceleration time-histories, evident in 

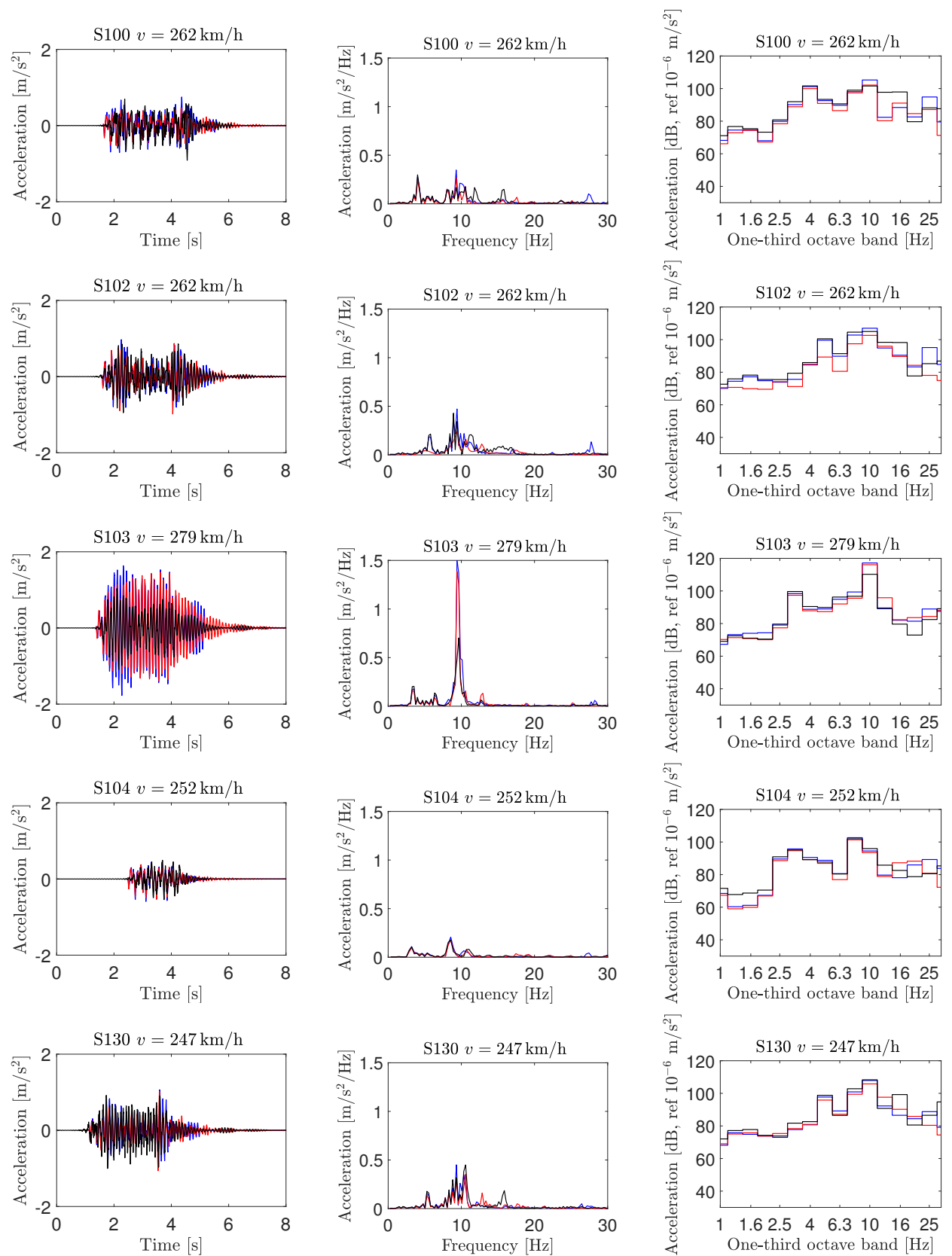

Figure 13: (Left) Time history, (center) frequency content and (right) one-third octave band content of the acceleration at point 5 induced by S100, S102, S103, S104 and S130 Renfe class trains at different speeds: experimental (black line) vs. orthotropic (red line) and isotropic plate-beams (blue line) numerical models. 

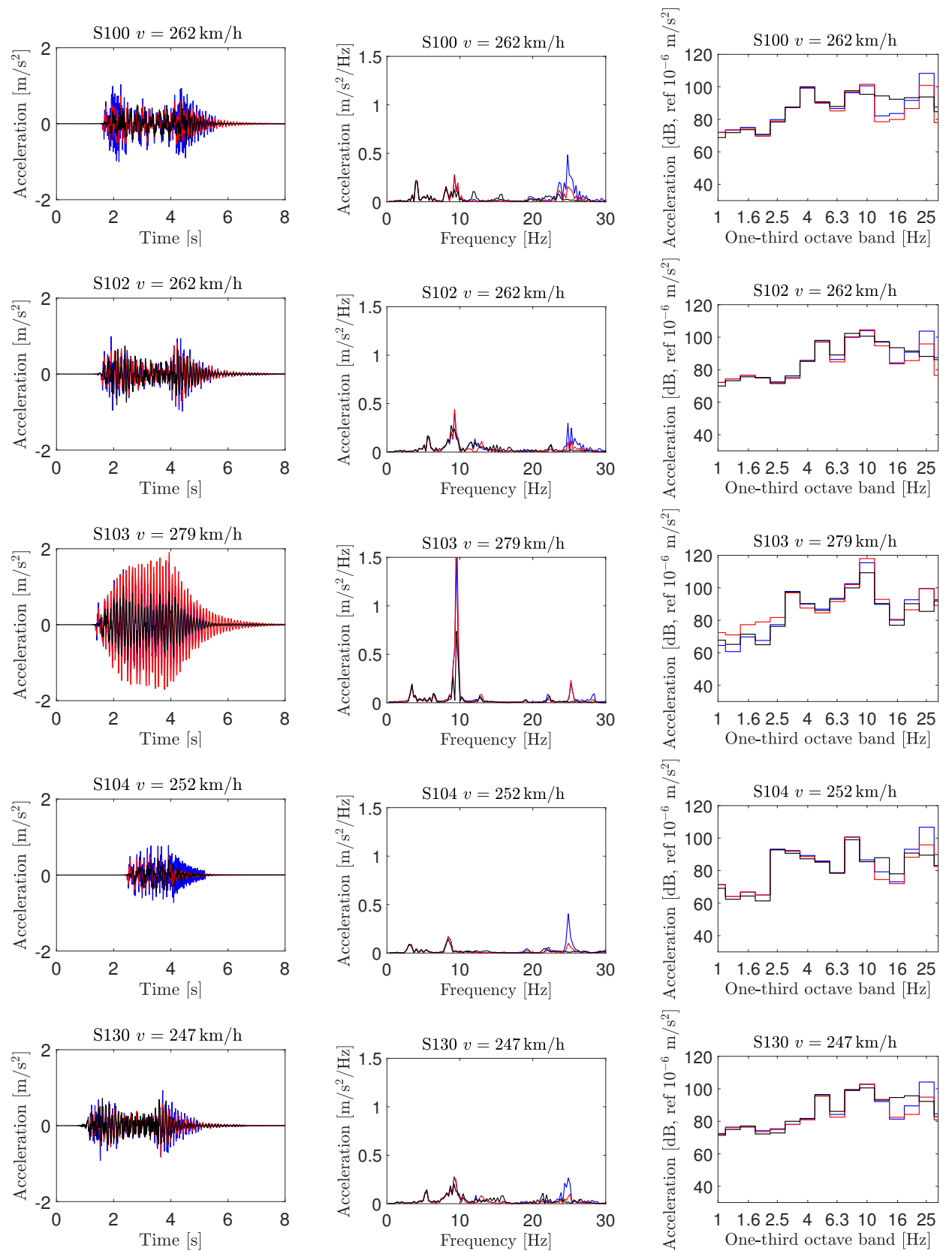

Figure 14: (Left) Time history, (center) frequency content and (right) one-third octave band content of the acceleration at point 6 induced by S100, S102, S103, S104 and S130 Renfe class trains at different speeds: experimental (black line) vs. orthotropic (red line) and isotropic plate-beams (blue line) numerical models. 

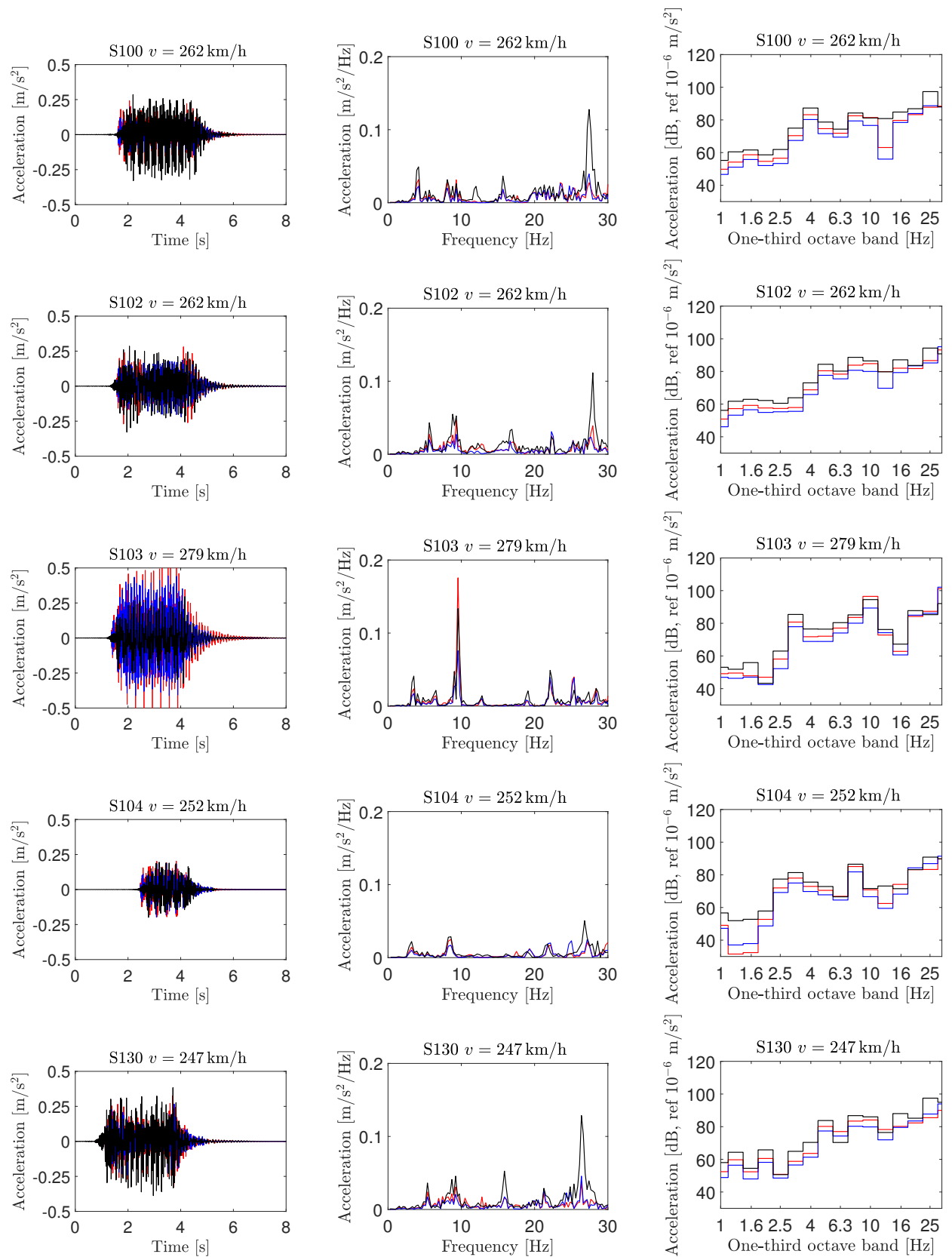

Figure 15: (Left) Time history, (center) frequency content and (right) one-third octave band content of the acceleration at point 10 induced by S100, S102, S103, S104 and S130 Renfe class trains at different speeds: experimental (black line) vs. orthotropic (red line) and isotropic plate-beams (blue line) numerical models. 
all the sensors, and also from the predominant contribution of the fundamental peak in the frequency domain. In this situation the deck undergoes three cycles of first bending oscillations between the passage of two consecutive coaches. Bracea I bridge response is mainly due to the fundamental mode and behaves as a beam-type structure only under the circulation of this train. The bridge also undergoes a second resonance of the torsion mode induced by S130 train. Both resonances are perceptible in the experimental records and are also reproduced by the numerical models. As expected, the resonance of the fundamental mode excited by the S103 train is much more noticeable in terms of vibrational amplitudes than the resonance of the first torsional mode induced by the S130 train. As previously mentioned, in the latter case the circulation of the train occurs closer to a cancellation condition.

The numerical predictions are considerably accurate, especially in the sensors located at midspan or at a quarter of span and in the frequency range $1-10 \mathrm{~Hz}$. The frequency peak associated to the bogie distance excitation, $f_{b}$, is perceptible in all the records, both in the sensors installed far from the abutments or close to them, and adopts the values: $3.9,5.6,4.5,3.7$ and $5.2 \mathrm{~Hz}$ for the trains S100, 102, 103, 104 and S130, respectively. A high contribution associated to the fundamental bending mode of the structure is also present in all the records and well predicted numerically by both models. The contribution of the first torsion mode is also visible both experimentally and numerically at certain locations i.e. S104 and S130 comparing the response of sensors 5 (Figure 14) and 6 (Figure 15).

In these cases it may be observed that the orthotropic plate model reproduces the frequency contents associated to the torsion mode more accurately than the isotropic plate + beams model. The latter predicts a slightly lower frequency peak, which is consistent with the lower torsional natural frequency predicted by this particular model. Nevertheless, the amplitude of the torsional vibration predicted by both numerical models is of the same order

The difference between the accuracy of the predictions of the two numerical models is minor at midspan (sensors 5 and 6 ) especially in the frequency range $[1-15] \mathrm{Hz}$, approximately. This indicates that the uniform distribution of the girders and bearings elastic stiffnesses is not determinant for the calculation of the response at the deck centre for moderate frequency contents. The models predictions differ to a higher extent at higher frequencies. In sensors 5 and 6 it may be noticed how the isotropic plate + beams model generally overestimates the acceleration response between $25 \mathrm{~Hz}$ and $30 \mathrm{~Hz}$, leading to some peaks which are not present in the experimental response, while the orthotropic model remains closer to the measured response of the structure in this frequency range.

Far from the abutments the numerical models tend to overestimate the bridge response. This happens especially at resonance, where the interaction between the bridge and the vehicle suspension systems, not considered in the numerical models, may be causing a reduction in the structural response [4]. Also, the variation of the structure damping with the amplitude of the vibrations may affect the amplitude at resonance, as stated by some authors [5].

The acceleration response measured by the sensors located close to the abutments, characterised by frequency contributions in the range $[25-30] \mathrm{Hz}$, is generally underestimated by the numerical models. The frequency peaks associated to the excitation and bridge natural frequencies detected in sensors 5 and 6 are also perceptible in sensor 10 . The fitting between measured and predicted levels of acceleration is worse at the sensors 
close to the abutments, especially at those separated from the longitudinal axis of the deck. The numerical models underestimate the acceleration at the abutments in all the frequency bands and for all the train passages. This could be due to the following facts: (i) a constant moving load model is used in the numerical models and vehicle-structure interaction is disregarded; (ii) the distributive effects of the track components at the supports vicinity is simulated by applying an algorithm that modulates the axle load when it enters and exists the bridge [28], but the track components are not explicitly included in the models; and (iii) the effect of the SSI is more important but it is not considered in this analysis. These simplifications affect the fitting of the numerical and experimental results close to the supports to a greater extent but are not relevant closer to the mid-span section, where the maximum acceleration of the bridge takes place.

Finally as the acceleration levels at the abutments are not particularly significant in terms of structural safety, the vertical displacement is represented and compared to numerical predictions at these areas. To this end, the experimentally measured acceleration is filtered applying a Butterworth zero-phase filter with a cut-off frequency of $1 \mathrm{~Hz}$ and integrated twice. Therefore, it should be indicated that the comparison between numerical and experimental results at frequencies lower than $1 \mathrm{~Hz}$ cannot be rigorously done. Figure 17 shows the vertical displacement at sensor 10 obtained by double integration of the experimental acceleration along with the numerical predictions. The correspondence between the numerical displacements and the experimental ones improves compared to the acceleration case as the response is mainly governed by low frequency contributions. Even though both numerical models underestimate the experimental response in terms of displacements, the isotropic plate + beams model provides a narrower fit with the real response. This is related to the uniform distribution of stiffness and vertical flexibility of the girders and the support bearings admitted in the orthotropic plate model, which affects to a higher extent the comparison at the abutments than that at the mid-span section, where the overall structural response is much higher. This conclusion is consistent with the observations at the rest of the sensors installed close to the bridge supports. It should be noted that as the experimental displacement time-history response has been obtained by integration of the acceleration, and the frequency response lower than $1 \mathrm{~Hz}$ has been filtered, the static component of the train axles weight is not present in the experimental displacement. This explains the difference in the values of the response between the experimental and the numerical registers. 

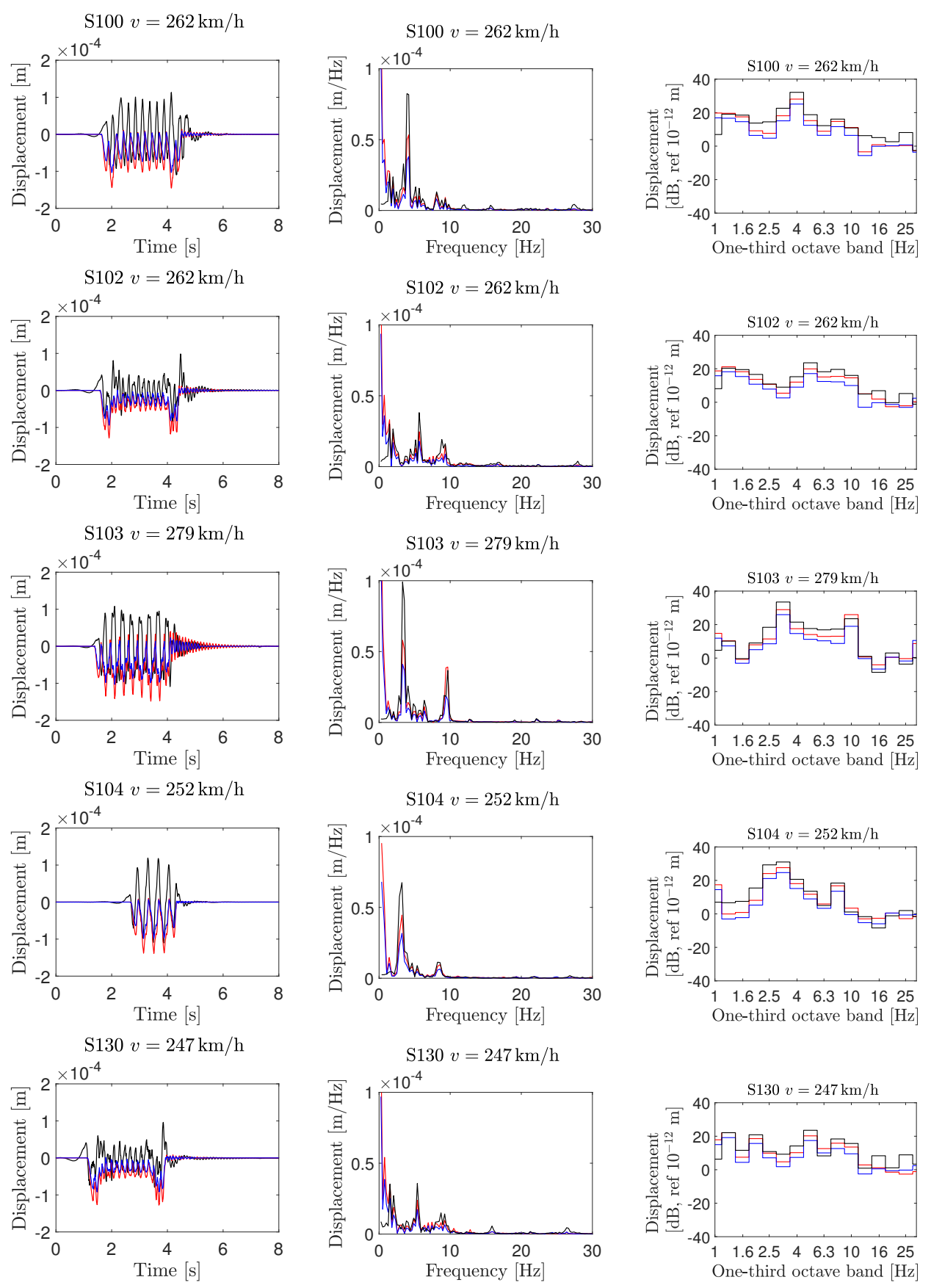

Figure 16: (Left) Time history, (center) frequency content and (right) one-third octave band content of the displacement at point 10 induced by S100, S102, S103, S104 and S130 Renfe class trains at different speeds: experimental (black line) vs. orthotropic (red line) and isotropic plate-beams (blue line) numerical models. 


\subsection{Overall maximum acceleration at the platform}

(a)

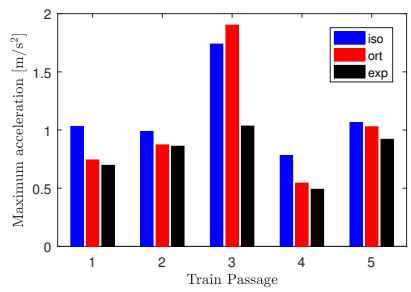

(c)

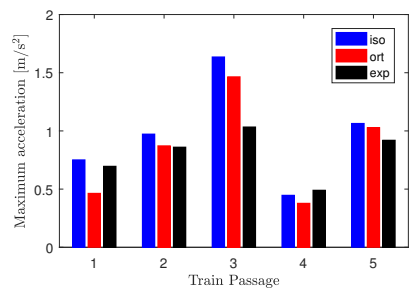

(b)

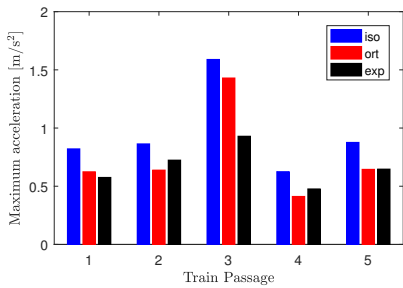

(d)

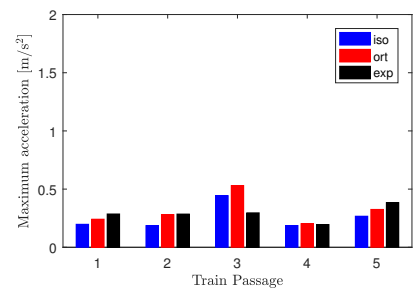

Figure 17: Maximum acceleration induced for (1) S100, (2) S102, (3) S103, (4) S104 and (5) S130 Renfe class trains at different speeds: (a) Overall maximum, (b) Sensor \#4, (c) Sensor \#5 and (d) Sensor \#10.

In this section the accuracy in the prediction of the maximum vertical acceleration given by the two numerical models is analysed. In Figure 18 the maximum vertical acceleration is represented for the five train passages: (1) S100, (2) S102, (3) S103, (4) S104 and (5) S130. Figures 18(b,c,d) show the maximum response at sensors 4, 5 and 10 respectively. In Figure 18(a) the overall maximum acceleration considering all the installed sensors is represented for each train passage.

When the bridge does not undergo resonance (circulation of trains S100, S102 and S104) the overall maximum acceleration predicted by the orthortopic plate model is remarkably accurate, overestimating the maximum experimental response in less than $11 \%$. When resonance occurs, the orthotropic plate model overestimates the experimental maximum acceleration in a much higher proportion, especially under the passage of the S103 train for which the maximum acceleration predicted is almost twice the maximum measured value. As per the isotropic plate + beams model, the prediction of the overall maximum acceleration when resonance does not occur is less accurate when compared to the orthotropic model, leading to a higher overestimation of the maximum response. In the case of resonance, the isotropic plate + beams model overestimates the maximum acceleration in a similar proportion to the orthortopic model for the S103 and for the S130 train passages. As already mentioned, vehicle-structure interaction effects, not taken into account in the numerical models, may be responsible for the overestimation of the numerical models at resonance because, as reported by some authors [4], the bridge response reduces due to the interaction with the vehicle suspension systems and this effect is most noticeable under resonance conditions.

Regarding the accuracy of the prediction at the different sensors it may be noted that out of resonance the orthotropic plate model provides a very accurate representation of the maximum acceleration independently of the platform location. On the other hand, 
the isotropic plate + beams model leads to a better prediction of the maximum response at mid-span (points 56 and 7) than at three quarters of the span (point 4).

At the supports (sensor 10) the maximum acceleration measured experimentally is slightly higher than that predicted by the numerical models except in the case of the S103 passage. Nevertheless, the difference between experimental and numerical maximum values is very limited at this sensor.

Finally, Figure 19 represents the mean value of the difference between experimental and numerical one-third octave band contents of the acceleration considering all the sensors except those located at the abutments (i.e. sensors 4, 5,6 and 7). In each frequency band the red line stands for the mean value of the difference between the experimental response and that given by the isotropic plate + beams model in the five sensors and for the five train passages. Likewise, the horizontal blue lines in each frequency band indicate the mean value of the difference between the experimental response and that predicted by the orthotropic plate model for all sensors and train passages. The maximum difference (not shown) between experimental and numerical accelerations falls within the $\pm 20 \mathrm{~dB}$. Below $15 \mathrm{~Hz}$ the maximum difference falls within the $\pm 10 \mathrm{~dB}$. The highest differences between experimental results and numerical predictions appear for the highest frequencies as it is apparent from Figure 19.

\section{Conclusions}

The dynamic behaviour of short span railway bridges under High-Speed traffic, and the adequateness of two numerical models in the prediction of the vibratory response is addressed. An existing bridge that belongs to the Madrid-Sevilla High-Speed railway line is selected. The structure is composed by two identical simply-supported bays of $15.25 \mathrm{~m}$ and has a remarkable obliqueness of $45^{\circ}$. Due to the deck geometry, lightness and skew angle the structure is prone to experience (i) important vertical vibration levels, and (ii) a plate-type behaviour characterized by the contribution of modes different from the longitudinal bending ones in the $[0,30] \mathrm{Hz}$ frequency range.

An experimental campaign is performed at the site in order to characterize the soil and the structure dynamic behaviour. The $\mathrm{P}$ and $\mathrm{S}$ wave velocities along with the densities and damping ratios are identified for the soil layers, resulting in an extremely stiff soil type. The bridge deck is monitored and its vertical acceleration response is obtained under ambient vibration and under the circulation of five different trains travelling at velocities in the range $[247-279] \mathrm{km} / \mathrm{h}$. Two numerical Finite Element models are implemented for the bridge: an orthotropic plate model, which admits a uniform distribution of the girders and elastic bearings stiffness, and an isotropic plate + beams model where the slab, girders and supports are explicitly simulated. In both models the usual simplifications admitted in engineering practice are assumed and vehicle-rail-structure interaction is disregarded. The bridge response is reproduced with the aim of (i) evaluating the structural response under High-Speed traffic and (ii) analysing the adequateness of the numerical models when it comes to predicting the maximum transverse response and assessing the Serviceability Limit State of vertical acceleration.

The main conclusions concerning the structure performance are: 


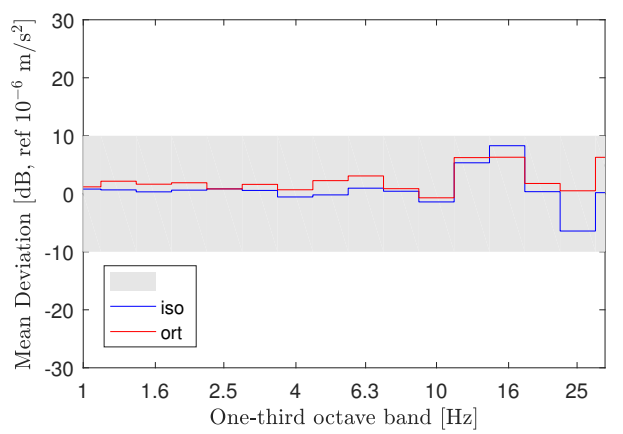

Figure 18: Mean value of the difference between the experimental and numerical one-third octave band contents of the acceleration at sensors 4,5,6 and 7 induced all train passages.

- Under the circulation of the trains that operate Madrid-Sevilla High-Speed line, the maximum vertical acceleration at the platform of Bracea I bridge does not exceed the limit of $3.5 \mathrm{~m} / \mathrm{s}^{2}$ established by standards for ballasted tracks.

- Among the monitored train passages, the bridge experiences a clear third resonance of the fundamental mode when Renfe Class S103 train crosses the structure at $279 \mathrm{~km} / \mathrm{h}$. The phenomenon is detected in all the sensors and is characterized by a progressive increase of the vertical response and the prevalence of the first mode in the frequency domain. In this case, resonance occurs far from a cancellation condition leading to a very noticeable amplification of the response.

- A second resonance of the first torsion mode can also be detected when Renfe Class S130 train crosses the bridge at $247 \mathrm{~km} / \mathrm{h}$ but its effects are much less appreciable. Both aforementioned resonances are associated to the passengers' cars lengths. In this case, resonance takes place close to a cancellation condition, so the associated amplitude is limited.

- The identified properties of the soil at the bridge site show a saturated soil with a remarkably high stiffness. Therefore soil-structure interaction is not expected to affect the dynamic response of the bridge to a big extent. This conclusion is consistent with the similarity between the experimental and numerical natural frequencies obtained.

The main conclusions regarding the adequateness of the numerical models are:

- Five natural frequencies of the bridge are identified from the ambient vibration response below $30 \mathrm{~Hz}$. The numerical models predict these values with errors lower than $5 \%$ in the orthotropic model case and lower than $8 \%$ in the case of the isotropic plate + beams model. AutoMAC values higher than 0.93 (Table 4) are obtained for the first bending and first torsion modes with both numerical models, showing a good correspondence between experimental and numerical results.

- When the bridge undergoes a clear resonance, as the one induced by train S103 circulating at $279 \mathrm{~km} / \mathrm{h}$, the numerical models overestimate the maximum acceleration at the platform, presumably due to effects such as vehicle-structure interaction which are most significant at resonance and are not included in the models. 
- When the bridge deck does not undergo resonance, several modes contribute to the vertical acceleration response and, as it was expected, the response greatly differs from that of a beam-type structure. This fact is related to different factors such as the bridge deck length-to-wide dimensions, the eccentricity of the excitation and the structure obliquity.

- The difference between the predictions of the two numerical models, orthotropic and isotropic + beams models is minor at mid-span, especially in the frequency range $[1,15] \mathrm{Hz}$, approximately. This indicates that the uniform distribution of the girders and bearings vertical stiffness admitted in the orthotropic plate model is not determinant for the calculation of the maximum response at the deck centre for moderate frequency contents.

- The fitting between measured and predicted levels of acceleration is worse at the sensors close to the abutments, especially at those separated from the longitudinal axis of the deck. The numerical models under-predict the acceleration at the abutments in all the frequency bands and for all the train passages. The use of a constant moving load model and a simplified algorithm in order to take into account the distributive effects of the track components at the supports vicinity affects these predictions. Nevertheless, these modelling issues are not relevant closer to the midspan section, where the maximum acceleration of the bridge takes place and the Serviceability Limit State of vertical acceleration is evaluated.

- The overall prediction of the maximum bridge acceleration under all the train passages is reasonably good for the orthotropic plate model when resonance does not take place. In this situation the model overestimates the maximum experimental response in less than $11 \%$. In the same cases, the isotropic plate + beams model overestimates the maximum acceleration in a higher proportion being less accurate. Under resonance, both models clearly overestimate the maximum overall acceleration. This may be related to vehicle-structure interaction effects and to a possible variation of damping with the vibration amplitudes.

- The influence of an adjacent deck, connected to the monitored one through the railway may be affecting the response close to the supports and will be evaluated in subsequent contributions.

\section{Acknowledgements}

The authors would like to acknowledge the financial support provided by (i) the Spanish Ministry of Economy and Competitiveness under the research project [BIA2013-43085P], (ii) the Andalusian Scientific Computing Centre (CICA) and (iii) Universitat Jaume I under the research project [P1-1B2015-54]. This work falls within the initiation of research project BIA2016-75042-C2 financed by the Spanish Ministry of Economy and Competitiveness.

\section{References}

[1] ERRI-D-214/RP9, Rail bridges for speeds $>200 \mathrm{~km} / \mathrm{h}$. Final report. Part A. Synthesis of the results of D214 research, European Rail Research Institute, 1999. 
[2] L. Frýba, Dynamic behaviour of bridges due to high-speed trains, Workshop Bridges for High-Speed Railways Porto (June 2004) 137-158.

[3] K. Liu, G. D. Roeck, G. Lombaert, The effect of dynamic train-bridge interaction on the bridge response during a train passage, Journal of Sound and Vibration 325 (1-2) (2009) $240-251$. doi:http://doi.org/10.1016/j.jsv.2009.03.021.

[4] A. Doménech, P. Museros, M. Martínez-Rodrigo, Influence of the vehicle model on the prediction of the maximum bending response of simply-supported bridges under high-speed railway traffic, Engineering Structures 72 (2014) 123 - 139. doi:http://doi.org/10.1016/j.engstruct.2014.04.037.

[5] M. Ülker-Kaustell, R. Karoumi, Influence of non-linear stiffness and damping on the train-bridge resonance of a simply supported railway bridge, Engineering Structures 41 (2012) 350 - 355 . doi:http://doi.org/10.1016/j.engstruct.2012.03.060.

[6] Y. Lu, L. Mao, P. Woodward, Frequency characteristics of railway bridge response to moving trains with consideration of train mass, Engineering Structures 42 (2012) 9 - 22 . doi:http://doi.org/10.1016/j.engstruct.2012.04.007.

[7] J. Rocha, A. Henriques, R. Calçada, Safety assessment of a short span railway bridge for high-speed traffic using simulation techniques, Engineering Structures 40 (2012) $141-154$ doi:http://doi.org/10.1016/j.engstruct.2012.02.024.

[8] M. Ülker-Kaustell, R. Karoumi, C. Pacoste, Simplified analysis of the dynamic soil-structure interaction of a portal frame railway bridge, Engineering Structures 32 (11) (2010) 3692 - 3698 . doi:http://dx.doi.org/10.1016/j.engstruct.2010.08.013.

[9] A. Romero, M. Solís, J. Domínguez, P. Galvín, Soil-structure interaction in resonant railway bridges, Soil Dynamics and Earthquake Engineering 47 (2013) 108 - 116, sI: José Manuel Roësset. doi:http://dx.doi.org/10.1016/j.soildyn.2012.07.014.

[10] G. Gu, Resonance in long-span railway bridges carrying TGV trains, Computers \& Structures 152 (2015) 185 - 199. doi:http://doi.org/10.1016/j.compstruc.2015.02.002.

[11] D. Cantero, R. Karoumi, Numerical evaluation of the mid-span assumption in the calculation of total load effects in railway bridges, Engineering Structures 107 (2016) 1 - 8 . doi:http://doi.org/10.1016/j.engstruct.2015.11.005.

[12] A. Doménech, M. Martínez-Rodrigo, A. Romero, P. Galvín, On the basic phenomenon of soilstructure interaction on the free vibration response of beams: Application to railway bridges, Engineering Structures 125 (2016) 254 - 265. doi:http://dx.doi.org/10.1016/j.engstruct.2016.06.052.

[13] R. Bebiano, R. Calçada, D. Camotim, N. Silvestre, Dynamic analysis of high-speed railway bridge decks using generalised beam theory, Thin-Walled Structures 114 (2017) $22-31$. doi:http://doi.org/10.1016/j.tws.2017.01.027.

[14] H. Xia, G. D. Roeck, N. Zhang, J. Maeck, Experimental analysis of a high-speed railway bridge under thalys trains, Journal of Sound and Vibration 268 (1) (2003) 103 - 113. doi:http://doi.org/10.1016/S0022-460X(03)00202-5.

[15] M.-S. Marefat, E. Ghahremani-Gargary, S. Ataei, Load test of a plain concrete arch railway bridge of 20-m span, Construction and Building Materials 18 (9) (2004) 661 - 667 . doi:http://doi.org/10.1016/j.conbuildmat.2004.04.025.

[16] C. Rebelo, L. S. da Silva, C. Rigueiro, M. Pircher, Dynamic behaviour of twin single-span ballasted railway viaducts - field measurements and modal identification, Engineering Structures 30 (9) (2008) 2460 - 2469. doi:http://dx.doi.org/10.1016/j.engstruct.2008.01.023.

[17] E. B. Flener, R. Karoumi, Dynamic testing of a soil-steel composite railway bridge, Engineering Structures 31 (12) (2009) 2803 - 2811. doi:http://doi.org/10.1016/j.engstruct.2009.07.028.

[18] K. Liu, E. Reynders, G. D. Roeck, G. Lombaert, Experimental and numerical analysis of a composite bridge for high-speed trains, Journal of Sound and Vibration 320 (1-2) (2009) $201-220$. doi:http://dx.doi.org/10.1016/j.jsv.2008.07.010.

[19] B. H. Kim, J. Lee, D. H. Lee, Extracting modal parameters of high-speed railway bridge using the TDD technique, Mechanical Systems and Signal Processing 24 (3) (2010) $707-720$. doi:http://doi.org/10.1016/j.ymssp.2009.11.010.

[20] J. Wallin, J. Leander, R. Karoumi, Strengthening of a steel railway bridge and its impact on the dynamic response to passing trains, Engineering Structures 33 (2) (2011) 635 - 646 . doi:http://doi.org/10.1016/j.engstruct.2010.11.022.

[21] J. Vega, A. Fraile, E. Alarcón, L. Hermanns, Dynamic response of underpasses for high-speed train lines, Journal of Sound and Vibration 331 (23) (2012) 5125 - 5140. doi:http://doi.org/10.1016/j.jsv.2012.07.005.

[22] D. Ribeiro, R. Calçada, R. Delgado, M. Brehm, V. Zabel, Finite element model updating of a bowstring-arch railway bridge based on experimental modal parameters, Engineering Structures 40 
(2012) 413 - 435. doi:http://dx.doi.org/10.1016/j.engstruct.2012.03.013.

[23] C. Johansson, N. Nualláin, C. Pacoste, A. Andersson, A methodology for the preliminary assessment of existing railway bridges for high-speed traffic, Engineering Structures 58 (2014) $25-35$. doi:http://doi.org/10.1016/j.engstruct.2013.10.011.

[24] J. Malveiro, D. Ribeiro, R. Calçada, R. Delgado, Updating and validation of the dynamic model of a railway viaduct with precast deck, Structure and Infrastructure Engineering 10 (11) (2014) 1484-1509. doi:10.1080/15732479.2013.833950.

[25] C. Costa, D. Ribeiro, P. Jorge, R. Silva, A. Arêde, R. Calçada, Calibration of the numerical model of a stone masonry railway bridge based on experimentally identified modal parameters, Engineering Structures 123 (2016) 354 - 371. doi:http://doi.org/10.1016/j.engstruct.2016.05.044.

[26] J. Park, S. Ahn, J. Kim, H.-I. Koh, J. Park, Direct determination of dynamic properties of railway tracks for flexural vibrations, European Journal of Mechanics - A/Solids 61 (2017) $14-21$. doi:http://doi.org/10.1016/j.euromechsol.2016.08.010.

[27] P. Mellat, A. Andersson, L. Pettersson, R. Karoumi, Dynamic behaviour of a short span soilsteel composite bridge for high-speed railways-field measurements and FE-analysis, Engineering Structures 69 (2014) 49 - 61. doi:http://dx.doi.org/10.1016/j.engstruct.2014.03.004.

[28] M. Martínez-Rodrigo, J. Lavado, P. Museros, Dynamic performance of existing high-speed railway bridges under resonant conditions retrofitted with fluid viscous dampers, Engineering Structures 32 (3) (2010) 808-828. doi:http://dx.doi.org/10.1016/j.engstruct.2009.12.008.

[29] CEN, EN 1991-2, Eurocode 1: Actions on Structures - Part 2: Traffic loads on bridges, European Committee for Standardization, Brussels, 2002.

[30] CEN/TC250, Eurocode: Basis of structural design. Annex A2: Application for bridges. Final version, European Committee for Standardization, Brussels, 2005.

[31] A. Cusens, R. Pama, Bridge deck analysis, John Wiley \& Sons, 1975.

[32] E. Humbly, Bridge deck behaviour, J Halsted Press, a division of John Wiley \& Sons, 1976.

[33] R. West, Recommendations on the use of grillage analysis for slab and pseudo-slab bridge decks, Cement and concrete association, 1973.

[34] S. A. Badsar, M. Schevenels, W. Haegeman, G. Degrande, Determination of the material damping ratio in the soil from SASW tests using the half-power bandwidth method, Geophysical Journal International 182 (3) (2010) 1493-1508. doi:10.1111/j.1365-246X.2010.04690.x.

[35] M. Schevenels, S. François, G. Degrande, EDT: An elastodynamics toolbox for MATLAB, Computers \& Geosciences 35 (8) (2009) 1752 - 1754. doi:http://dx.doi.org/10.1016/j.cageo.2008.10.012.

[36] Ministerio de transporte, turismo y comunicaciones, Nuevo acceso ferroviario a Andalucía. Proyecto de infraestructura y vía. Estudio geológico y geotécnico, Gobierno de España, 1987.

[37] E. Reynders, System identification methods for (operational) modal analysis: Review and comparison, Archives of Computational Methods in Engineering 19 (1) (2012) 51-124. doi:10.1007/s11831012-9069-x.

[38] R. J. Allemang, D. L. Brown, Correlation coefficient for modal vector analysis, in: Proceedings of International Modal Analysis I, 1982, pp. 110-116.

[39] R. S. Pappa, K. B. Elliott, Consistent-mode indicator for the eigensystem realization algorithm, Journal of Guidance, Control, and Dynamics $16 \quad$ (5) (1993) 852 - 858 . doi:http://dx.doi.org/10.2514/3.21092.

[40] P. Museros, E. Moliner, M. Martínez-Rodrigo, Free vibrations of simply-supported beam bridges under moving loads: Maximum resonance, cancellation and resonant vertical acceleration, Journal of Sound and Vibration 332 (2012) 326-345. 